Article

\title{
Cluster Analysis of the Wind Events and Seasonal Wind Circulation Patterns in the Mexico City Region
}

\author{
Susana Carreón-Sierra ${ }^{1, \dagger}$, Alejandro Salcido ${ }^{1, \dagger, *}$, Telma Castro ${ }^{2, \dagger}$ and \\ Ana-Teresa Celada-Murillo ${ }^{1, \dagger}$
}

1 Instituto de Investigaciones Eléctricas, División de Energías Alternas, Reforma 113, Palmira, Cuernavaca 62490, Mexico; E-Mails: susana.carreon@iie.org.mx (S.C.-S.); atcelada@iiie.org.mx (A.-T.C.-M.)

2 Centro de Ciencias de la Atmósfera, Universidad Nacional Autónoma de México, Circuito Exterior, Ciudad Universitaria, Mexico 04510, Mexico; E-Mail: telma@atmosfera.unam.mx

$\dagger$ These authors contributed equally to this work.

* Author to whom correspondence should be addressed; E-Mail: salcido@iie.org.mx; Tel.: +52-777-362-3811 (ext. 7087).

Academic Editor: Robert Talbot

Received: 8 May 2015 / Accepted: 14 July 2015 / Published: 24 July 2015

\begin{abstract}
The residents of Mexico City face serious problems of air pollution. Identifying the most representative scenarios for the transport and dispersion of air pollutants requires the knowledge of the main wind circulation patterns. In this paper, a simple method to recognize and characterize the wind circulation patterns in a given region is proposed and applied to the Mexico City winds (2001-2006). This method uses a lattice wind approach to model the local wind events at the meso- $\beta$ scale, and hierarchical cluster analysis to recognize their agglomerations in their phase space. Data of the meteorological network of Mexico City was used as input for the lattice wind model. The Ward's clustering algorithm with Euclidean distance was applied to organize the model wind events in seasonal clusters for each year of the period. Comparison of the hourly population trends of these clusters permitted the recognition and detailed description of seven circulation patterns. These patterns resemble the qualitative descriptions of the Mexico City wind circulation modes reported by other authors. Our method, however, permitted also their quantitative characterization in terms of the wind attributes of velocity, divergence and vorticity, and an estimation of their seasonal and annual occurrence probabilities, which never before were quantified.
\end{abstract}


Keywords: urban winds; wind patterns; lattice wind models; cluster analysis

\section{Introduction}

The purpose of this work is to gain insight into the identification and characterization of the Mexico City wind circulation patterns on a seasonal basis. The knowledge of local wind events in a given region, their classification, and the identification of their possible circulation patterns is important for different applications: weather, climate, wind resource assessment, air pollution, bioclimatology, and urban planning, among others. In air pollution studies, for example, characterizing wind patterns provides a basis for understanding the transport and dispersion of pollutants, and therefore to evaluate the possibility of impact on the immediate surroundings of the sources or even on the neighboring urban and rural settlements.

Mexico City is the core of one of the largest world megacities and also one of the most polluted. Air pollution in this megacity is mainly related to the emissions that stem from the internal combustion vehicular traffic (around 80\%), but is also strongly related to the physiographic features of the region. The city, tropical in latitude $\left(19.00^{\circ}-19.60^{\circ} \mathrm{N}\right)$, is located in an elevated $(2240 \mathrm{~m})$ basin surrounded almost entirely by high altitude mountains, with only two ventilation openings at its the south and north sides (Figure 1). Given these topographic features, air pollutants, particularly during winter and spring, may remain trapped inside the basin for several days. Given its tropical location, however, solar irradiance is strong ( $\sim 900 \mathrm{~W} / \mathrm{m}^{2}$ at noon) throughout the year [1], and mixing height frequently reaches values up to $2600 \mathrm{~m}$ (or even higher) above ground [2]. These elevated mixing heights provide favorable conditions for transport of pollution towards the surrounding cities, such as the urban settlements of Morelos [3].
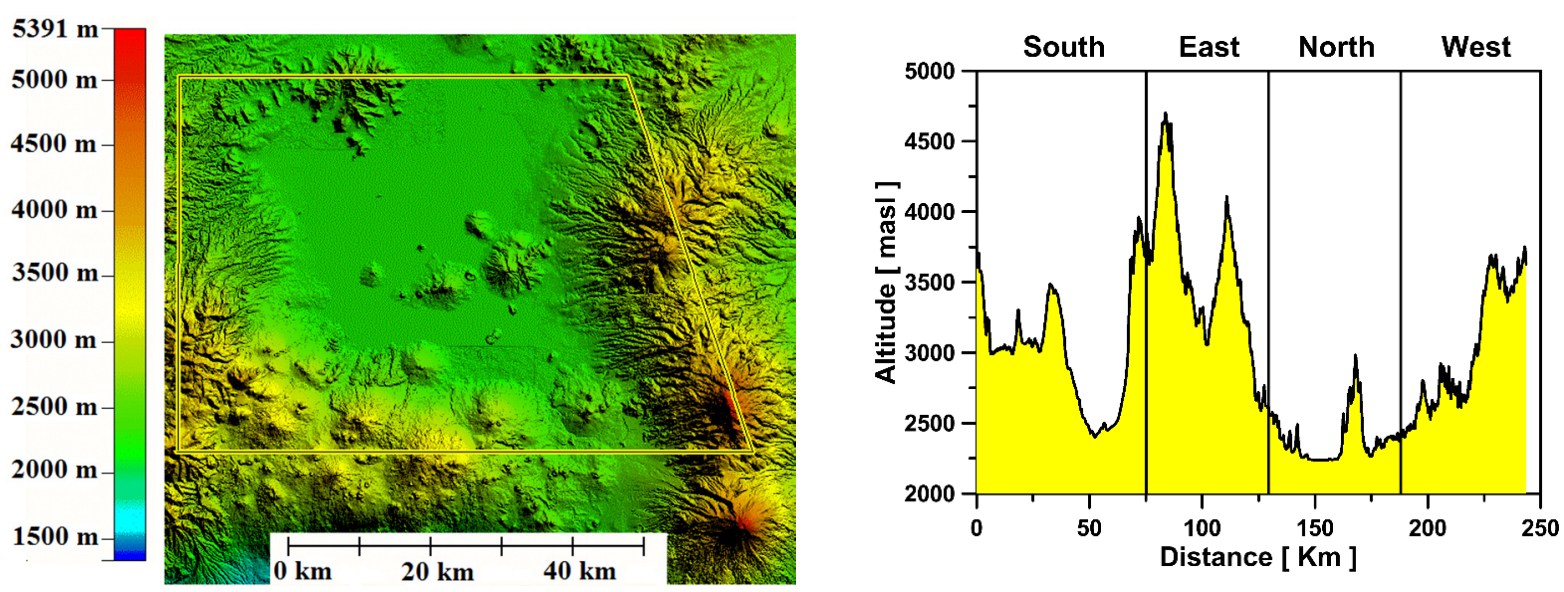

Figure 1. Altitude profile of the surrounding mountains of the Mexico City basin. The ventilation openings of the city at south and north sides of the basin are observed.

On the other hand, the urban morphology of Mexico City has changed significantly in the last 15 years. Particularly, in the period 2001-2006, when the local government conducted several urban, housing and rescuing policies related to the heritage of Mexico City's historic centre, which coincided with the construction of several vehicular corridors, skyscrapers, and other buildings. As a consequence, 
the urbanized area grew 495 ha per year, and around 400 ha of ecological reserve was lost per year [4]. These urban morphology modifications induce mechanical and thermal processes that change the local wind circulation, affect the local urban climate, and intensify the urban heat island effect [5].

The local wind behavior in the Mexico City Metropolitan Area (MCMA), and its relation to driving forces, air pollution, and urban climate have been studied extensively on an episode-by-episode basis for almost three decades. Most of the studies, however, have been performed using small wind data sets obtained from short-term experimental campaigns with a variety of different approaches. Examples of the more relevant works are the following: Jaúregui [6] described the interactions between the Mexico City local winds and air pollution for a period of 22 winter days (7-28 February 1986). Bossert [7], using the Regional Atmospheric Modeling System (RAMS), investigated the mesoscale flow structure over the Mexico City region for a three day period in February 1991. Fast and Zhong [8] examined the meteorological processes associated with inhomogeneous ozone concentrations over Mexico City by using observations from a four week field campaign and a mesoscale dynamics and dispersion modeling system. During this field campaign, meteorological measurements of the spatial flow structure within the Mexico City basin were obtained for the first time. Doran et al. [9] described a boundary layer field experiment in the Mexico City basin performed from 24 February to 22 March 1997. They observed three thermally and topographically driven flow patterns that are consistent with the topographical and thermal forcing mechanisms that prevail in this region. Salcido et al. [2] performed a brief analysis of the statistical behavior of the convective mixing height using atmospheric sounding data between January and May of 1993 and 1994. De Foy et al. [10] studied the wind circulation patterns in the Mexico City basin and on the regional scale during a short-term campaign carried out in April 2003. Fast et al. [11] reported a meteorological overview of the MILAGRO campaigns (March 2006). Salcido et al. [12] and Celada-Murillo et al. [13] studied the main characteristics of local wind events that occurred during the MILAGRO campaign using a lattice wind model at the meso- $\beta$ scale; and Salcido et al. [14] reported a brief clustering analysis of the Mexico City wind states occurring during the same period.

Exceptions to this are the following studies: Klaus et al. [15] carried out an eigenvector (principal component) analysis of air quality and meteorological data from a network of 15 stations for the period from February to November 1995; this analysis identified four eigenvectors corresponding to north/south transport, east/west slope flows, centre/periphery drainage flows and northeast/southwest precipitation flows. Salcido et al. [1] performed the first long-term micrometeorological campaign in surface carried out in a three station network in Mexico City throughout 2001. Finally, de Foy et al. [16] reported a basin-scale study of the wind transport during the MILAGRO campaign and its comparison to climatology using cluster analysis on the period of March 2006 and in the period 1998-2006 of hourly surface wind data from the Mexico City atmospheric monitoring network (RAMA) for the warm dry season. They showed that March 2006 was representative of typical flow patterns experienced in the basin, and they could identify six episode types for the basin-scale circulation.

Beside these works, no other long term analysis of the Mexico City local winds have been carried out, and a simple and standard methodology for the Mexico City wind taxonomy has not emerged from the studies performed in all these years.

In atmospheric sciences, classification of circulation patterns has become a specific research area within synoptic climatology. In 2008, Huth et al. [17] published a review of the recent advances in this 
topic, emphasizing recent tendencies and developments in both the methodology and applications. Here, circulation classifications are put into a broader context within climatology, and the varied methodologies and approaches are systematized. Three basic groups of classifications are highlighted: subjective (or manual), mixed (hybrid), and objective (automated), and the roles of cluster analysis and principal component analysis in the classification process are clarified. Several recent methodological developments in circulation classifications are identified and described, such as the introduction of nonlinear methods, objectifying of subjective catalogs, efforts to optimize classifications, the need for carrying out their mutual comparisons, and the progress toward an optimum and unified classification method.

The cluster analysis method of atmospheric sciences has been used, in particular, to establish local climatology as well as to determine the wind circulation patterns associated with severe air pollution episodes. On the meteorological side, Davis and Walker [18], in 1992, using principal component analysis and a two-step clustering technique, presented the development and analysis of an automated spatial synoptic climatology for the western United States developed solely from rawinsonde data (1979-1988). Weber and Kaufmann [19] presented an automated classification method that makes use only of wind observations and does not require predefined circulation patterns, a priori rules, or spatial or temporal interpolation. They defined a distance measure between pairs of wind fields and performed a hierarchical cluster analysis with complete linkage that also provided an indication for the choice of an appropriate number of clusters. An application of the method was carried out using one month of hourly mean wind data from 49 stations in a meso- $\gamma$ scale experiment. Kaufmann and Weber [20], based on the previous work, developed a two-step method consisting of a first pass with the complete linkage method followed by clustering with the k-means algorithm. This has been further used and described for wind pattern classification over the Grand Canyon [21] and for surface winds in Switzerland [22]. Kastendeuch and Kaufmann [23] applied the method to identify terrain induced winds in valley environments. Kastendeuch and Najjar [24] further extended it to upper-air wind profiles.

In this paper, we proposed a simple and systematic method for recognizing and characterizing the wind circulation patterns that prevail in a given region. We carried out also its application to the Mexico City local wind events which occurred throughout the years 2001-2006. The method uses a lattice wind approach to model the local wind events at the meso- $\beta$ scale, and the Ward's algorithm of hierarchical cluster analysis to identify the agglomerations of the model wind events in their phase space. In another paper [25], we have carried out a detailed description of the lattice wind modeling of the Mexico City wind events for the same period with the purpose of characterizing and identifying the prevailing wind states from an individual standpoint, and to estimate their occurrence probabilities. It was performed by considering first a mapping of the set of continuous wind states to the set of discrete wind states that results from using simple discrete scales of measurement to describe the values of the state parameters. In the present paper, otherwise, working out directly with the set of continuous wind states, we applied hierarchical cluster analysis with the purpose of identifying groups of wind states with similar characteristics that could be considered as instances or cases of wind circulation patterns. Seven wind circulation patterns were identified and characterized in terms of the wind velocity components and the wind divergence and vorticity. The method permitted also an estimation of the occurrence probabilities of the wind patterns. The wind patterns we found are not only distinguished by obvious features like prevailing wind direction, but they differ in finer details like the convergence 
and vorticity of the flows, which may indicate the effects of topography, land use, and the existence of gravity winds from the surrounding mountains of the region.

\section{Methodology}

A three-step procedure was carried out for this study: (1) Mexico City wind events of the period 2001-2006 were described and characterized from the standpoint of a lattice wind modeling approach at the meso- $\beta$ scale [12-14]; (2) a hierarchical cluster analysis was applied to the model wind events in order to identify and characterize the clusters in which they organize themselves according to the Ward's similarity criterion [26,27]; and (3) a comparative analysis of the hourly population trends of these clusters and their mean wind circulation characteristics was carried out, allowing the identification of the wind circulation patterns that prevailed during the period. The procedure description is given below.

\subsection{The Mexico City Model Wind Events}

From the standpoint of the lattice wind modeling approach $[12,13]$, the region of interest is modeled as a $2 \mathrm{D}$ lattice domain made up of a given number $N$ of identical rectangular cells, and the local wind conditions at each lattice cell are described by four attributes (state parameters): the horizontal components of wind velocity, denoted by $(u, v)$, the wind divergence, denoted by $\gamma$, and the wind vorticity, denoted by $\omega$. Here, the values of these parameters at a given cell represent spatial averages of the physical properties over this cell, at a given time. Then, the quartet $(u, v, \gamma, \omega)$ represents a model wind event at a lattice cell (or the wind state at this cell). Within the framework of a lattice wind model with $N$ cells ( $N$-cell LWM), the wind condition (or wind state) of the system (the region of interest), at a given time $t$, is defined by a set of $N$ quartets $(u, v, \gamma, \omega):\{(u(t), v(t), \gamma(t), \omega(t)) k \mid k=1,2,3, \ldots N\}$. The inclusion of divergence and vorticity as additional state variables to describe the local wind condition endows the model with a slightly non-local character and permits recovering some of the wind information lost by the filtering of the spatial averaging process over a cell. The mean velocity and its mean tendencies of rotation and divergence are assumed to be known at each cell. The set of the wind states (or model wind events) that one can observe in the region of interest is determined by the regional topographical features in conjunction with all other particular driving forces prevailing there. Obviously, a quartet $(u, v, \gamma, \omega)$ is equivalent to a quartet $(\mathrm{U}, \theta, \gamma, \omega)$ where $\mathrm{U}$ and $\theta$ denote the speed and direction of the wind velocity. When discrete scales of measurement are used to express the values of the wind state parameters, the wind states are referred to as discrete wind states (DWS).

For the purposes of this work, the region of interest was the portion of Mexico City that is located at $19.3^{\circ}-19.6^{\circ} \mathrm{N}$ and $99.0^{\circ}-99.3^{\circ} \mathrm{W}$ (Figure 2), and the 1-cell and 4-cell LWMs were applied to model its local wind conditions. In the 1-cell LWM, the Mexico City wind conditions are described by the spatial averages of the wind parameters $(u, v, \gamma, \omega)$ over the selected region. This is the simplest LWM of Mexico City. On the other hand, in the 4-cell LWM, Mexico City is divided in the quadrants NE, NW, SW and SE, which are defined by the axes W-E (west to east) and S-N (south to north) of the reference frame whose origin is at the geometric centroid of the meteorological stations of the Mexico City atmospheric monitoring network. Given the topographic complexity of the mountains surrounding Mexico City (Figure 2), the 4-cell model is the next level of LWM that we can use to describe the 
Mexico City wind circulation because it takes into account, separately, the ventilation openings located at the west and east sides of the Sierra de Guadalupe at the north of the city, and also the opening located at the southeast of the Mexico basin. In this case, the local wind conditions at the city quadrants (or cells) are described by the quartets $(u, v, \gamma, \omega)_{\mathrm{NE}},(u, v, \gamma, \omega)_{\mathrm{NW}},(u, v, \gamma, \omega)_{\mathrm{sw}}$, and $(u, v, \gamma$, $\omega)$ SE. The geometric centers of the city quadrants were located as follows: NE quadrant: $\left(19.5^{\circ} \mathrm{N}, 99.1^{\circ}\right.$ W), NW quadrant: $\left(19.5^{\circ} \mathrm{N}, 99.2^{\circ} \mathrm{W}\right), \mathrm{SW}$ quadrant: $\left(19.4^{\circ} \mathrm{N}, 99.2^{\circ} \mathrm{W}\right)$, and SE quadrant: $\left(19.4^{\circ} \mathrm{N}\right.$, $\left.99.1^{\circ} \mathrm{W}\right)$. These cells were $14.0 \mathrm{~km}$ length in the west-east direction, and $18.5 \mathrm{~km}$ length in the south-north direction.

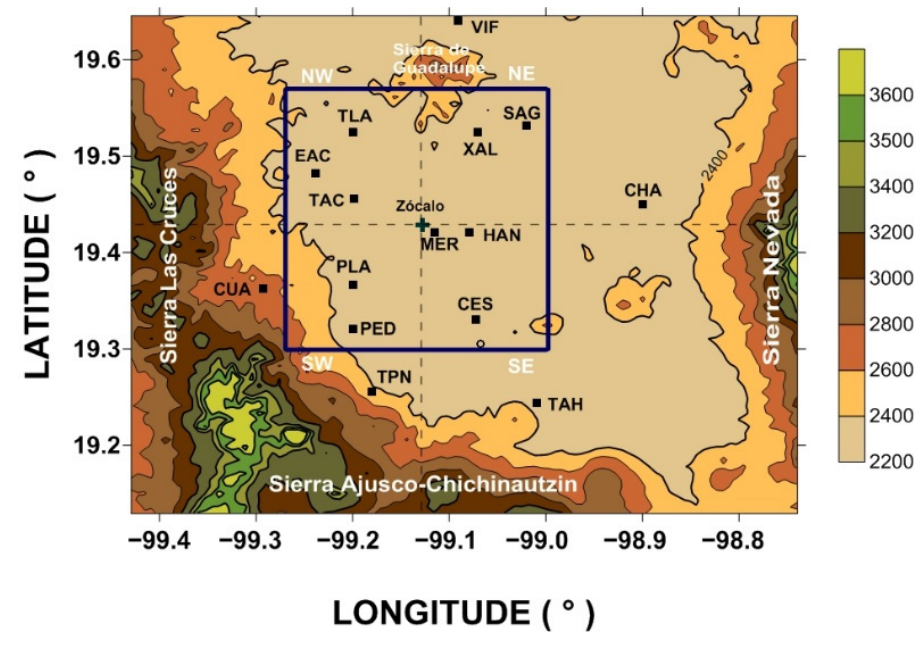

Figure 2. Spatial domain of study. The cells of the 1-cell (solid line rectangle) and the 4-cell (solid line rectangle divided by dashed lines) lattice wind models are shown.

For the aims of the study, the set $H$ of the hourly wind data provided by the meteorological network (REDMET) of the Secretaria del Medio Ambiente of Mexico City for the period 2001-2006 was considered as input for the 1-cell and 4-cell LWMs. This set contains the hourly values of wind speed (WSP) and wind direction (WDR) of the REDMET stations for the period 2001-2006. The average performances of the REDMET stations with respect to the availability of wind data in the period of interest are summarized in Table 1.

The general procedure to estimate the Mexico City wind states was as follows. (1) Each couple $(\operatorname{WSP}(s, h), \operatorname{WDR}(s, h)) \in H$ was converted to its equivalent couple $(\mathrm{U}(s, h), \mathrm{V}(s, h))$, where $\mathrm{U}$ and $\mathrm{V}$ are the horizontal components of the wind vector described by the couple (WSP, WDR). Here, $s$ and $h$ are indexes used to identify, respectively, the REDMET station where the wind event occurred ( $s=$ TAC, EAC, TLA, XAL, MER, PED, CES, PLA, HAN) and the occurrence time during the period of interest ( $h=1,2,3 \ldots 52,584$, for the period 2001-2006). The set of the couples $(\mathrm{U}(s, h), \mathrm{V}(s, h))$ will be denoted by $H^{*}$; (2) A $9 \times 9$ calculation grid $\mathrm{G}$ was defined over the spatial domain, and a Kriging technique of vector interpolation (boundary-constrained) was applied to $H^{*}$ to estimate the wind velocity components $\mathrm{u}(i, j, h)$ and $\mathrm{v}(i, j, h)$ at the nodes $(i, j)$ of $\mathrm{G}$ for each $h$; (3) These estimations were used to calculate the wind velocity components $(u, v)$, the wind divergence $\gamma$, and the wind vorticity $\omega$ at the cells of the $8 \times 8$ lattice, L, associated to the calculation grid G. At each cell $(p, q)$ of $\mathrm{L}$, the estimation of the parameters $u(p, q), v(p, q), \gamma(p, q)$ and $\omega(p, q)$ was carried out using the values of $(\mathrm{u}, \mathrm{v})$ at the four nodes located at the cell vertexes. Here, the 2D numerical definitions [25,28] of divergence 
and vorticity were used. The set $\{(u(p, q, h), v(p, q, h), \gamma(p, q, h), \omega(p, q, h)) \mid(p, q) \in L\}$ will be denoted by $\mathrm{W}(h)$. This set represents the model wind condition of the lattice $\mathrm{L}$ at hour $h$; (4) Finally, given a specific lattice wind model (1-cell LWM, 4-cell LWM, etc.) the wind condition at time $h$ at each cell $C_{n}$ of the LWM under consideration for Mexico City is estimated as the average of the quartets $(u(p, q, h), v(p, q, h), \gamma(p, q, h), \omega(p, q, h))$ of the $L$-cells contained in $C_{n}$. Positions of the REDMET stations are shown in Figure 2 as small solid squares.

Table 1. Annual performances of the meteorological stations relative to the availability (\%) of valid wind data. Period 2001-2006. Yellow cells: stations with an availability of valid data between $50 \%$ and $75 \%$. Red cells: stations with less than $50 \%$ of valid data. Gray cells: stations out of the spatial domain or with less than $75 \%$ of valid data; these stations were not considered.

\begin{tabular}{cccccccc}
\hline Station ID & $\mathbf{2 0 0 1}$ & $\mathbf{2 0 0 2}$ & $\mathbf{2 0 0 3}$ & $\mathbf{2 0 0 4}$ & $\mathbf{2 0 0 5}$ & $\mathbf{2 0 0 6}$ & Average \\
\hline TAC & 93 & 97 & 97 & 95 & 97 & 91 & 95 \\
EAC & 89 & 94 & 86 & 97 & 96 & 97 & 93 \\
SAG & 85 & 81 & 41 & 53 & 97 & 36 & 66 \\
TLA & 68 & 97 & 96 & 95 & 92 & 97 & 91 \\
XAL & 95 & 91 & 95 & 96 & 96 & 82 & 93 \\
MER & 92 & 94 & 90 & 92 & 95 & 96 & 93 \\
PED & 92 & 93 & 96 & 96 & 95 & 94 & 95 \\
CES & 81 & 92 & 92 & 93 & 91 & 92 & 90 \\
PLA & 87 & 95 & 95 & 94 & 94 & 94 & 93 \\
HAN & 92 & 85 & 92 & 93 & 96 & 18 & 79 \\
VIF & 68 & 89 & 94 & 96 & 95 & 96 & 90 \\
CUA & 84 & 86 & 97 & 99 & 96 & 75 & 89 \\
TPN & 63 & 76 & 43 & 0 & 34 & 55 & 45 \\
CHA & 85 & 87 & 86 & 89 & 93 & 91 & 89 \\
TAH & 94 & 91 & 93 & 98 & 97 & 31 & 84 \\
\hline
\end{tabular}

A simple illustration of wind circulation in a given region is supplied by the Wind Direction State (WDS) concept $[3,12,13,25]$ as long as the 4-cell lattice wind model is used. In this case, Mexico City is modeled as a rectangular $2 \times 2$ lattice domain, where each cell represents a quadrant of the city. The wind conditions at quadrants NE, NW, SW, and SE of the city can be described by the quartets (U, $\theta$, $\gamma, \omega)_{\mathrm{NE}},(\mathrm{U}, \theta, \gamma, \omega)_{\mathrm{NW}},(\mathrm{U}, \theta, \gamma, \omega)_{\mathrm{SW}}$, and $(\mathrm{U}, \theta, \gamma, \omega)_{\mathrm{SE}}$, respectively. Then, the WDS of the city is defined by the four wind directions $\theta_{\mathrm{NE}}, \theta_{\mathrm{NW}}, \theta_{\mathrm{Sw}}$, and $\theta_{\mathrm{SE}}$ in the cells. Whenever the value of wind direction is expressed in terms of the 8-sectors scale (N, NE, E, SE, S, SW, W, NW), the WDS allows a very simple but illustrative pictorial view of the wind circulation in the city. The WDS, in this case, is represented by a $2 \times 2$ array of small squares (representing the city quadrants), each one with an arrow inside that indicates the wind direction according to Table 2.

Table 2. Categories of the 8-sector wind direction scale.

\begin{tabular}{ccccccccc}
\hline \multirow{2}{*}{ Wind Direction } & N & NE & E & SE & S & SW & W & NW \\
\cline { 2 - 8 } & $\downarrow$ & $\swarrow$ & $\leftarrow$ & $\nwarrow$ & $\uparrow$ & $\nearrow$ & $\rightarrow$ & $\searrow$ \\
\hline
\end{tabular}




\subsection{Cluster Analysis of the Mexico City Wind States}

Within the framework of the lattice wind modeling approach, a Euclidean distance between any two cell wind states $\mathbf{S}_{\mathbf{1}}$ and $\mathbf{S}_{\mathbf{2}}$ is defined as follows

$$
D\left(\mathbf{S}_{1}, \mathbf{S}_{2}\right)=\sqrt{\Lambda^{2}\left[\left(u_{2}-u_{1}\right)^{2}+\left(v_{2}-v_{1}\right)^{2}\right]+\Gamma^{2}\left(\gamma_{2}-\gamma_{1}\right)^{2}+\Omega^{2}\left(\omega_{2}-\omega_{1}\right)^{2}}
$$

where $\Lambda, \Gamma$ and $\Omega$ are convenient scaling factors that guarantee that each state parameter contributes to the distance calculation according to its perceived importance [29]. This Euclidean distance can be used as a similarity criterion for analyzing the clustering of the wind states in the phase space $(u, v, \gamma, \omega)$.

Cluster analysis is a simple and convenient method for identifying homogenous groups of objects called clusters [27,29]. The objects in a specific cluster share many characteristics, but are very different to objects not belonging to that cluster. The first step of the cluster analysis procedure is to decide which clustering variables will be used to describe the data objects. The objective of cluster analysis is to identify groups of objects that are very similar with regard to the clustering variables and assign them into clusters. After having decided on the clustering variables, it is required to choose the clustering algorithm to form the groups of objects (clusters).

In Sections 2.2.1-2.2.4, the general characteristics of the cluster analysis procedure that we have followed in practice are described.

\subsubsection{Data Objects}

The set of data objects used for the cluster analysis was $\{(u(h), v(h), \gamma(h), \omega(h)) \mid h=1,2 \ldots$ $52,584\}$. This set, which will be denoted by E1C, comprises the 52,584 wind states $(u, v, \gamma, \omega)$ obtained through the application of the 1-cell LWM to Mexico City with the hourly wind data of the period 2001-2006. Each year of data was divided in seasonal periods: January-March (winter), April-June (spring), July-September (summer), and October-December (autumn), and considered separately from the other years during the analysis.

\subsubsection{Scaling of the Data Objects}

For the purpose of the cluster analysis, the quartets $(u, v, \gamma, \omega)$ of E1C were scaled according to the relations expressed by Equation (2), where the reciprocals of the maxima of the absolute values of wind speed, wind divergence, and wind vorticity were used as scaling factors.

$$
(u, v) \rightarrow \frac{(u, v)}{|w s p|_{\max }}, \gamma \rightarrow \frac{\gamma}{|\gamma|_{\max }}, \omega \rightarrow \frac{\omega}{|\omega|_{\max }}
$$

Here, wsp denotes the magnitude (speed) of the wind velocity vector defined by $(u, v)$. Of course, the bars of absolute value are completely irrelevant for wsp because it is a non-negative quantity by definition. These maxima were

$$
\begin{aligned}
|w s p|_{\max }= & \max \left\{w s p \mid w s p=\sqrt[2]{u^{2}+v^{2}}, \text { with }(u, v, \gamma, \omega) \in \mathcal{E}_{1 C}\right\}=5.89 \mathrm{~ms}^{-1} \\
& |\gamma|_{\max }=\max \left\{|\gamma| \mid(u, v, \gamma, \omega) \in \mathcal{E}_{1 C}\right\}=0.000446 \mathrm{~s}^{-1} \\
& |\omega|_{\max }=\max \left\{|\omega| \mid(u, v, \gamma, \omega) \in \mathcal{E}_{1 C}\right\}=0.000417 \mathrm{~s}^{-1}
\end{aligned}
$$


This kind of scaling defines an injection from the set of values of each wind parameter to the interval $[-1,1]$ preserving distinctness. It is intended to keep the data intact and to ensure that none of the wind state parameters will play a preferred role in the calculation of distance, which is very important here because of the big differences in order of magnitude between the values of the velocity components and those of the wind divergence and wind vorticity. We preferred this scaling procedure instead of the traditional Z-score standardization (where variables are re-calculated by subtracting the sample mean from the data and dividing by the standard deviation) because the measurement scales here are believed to be meaningful and because different scaling factors for the wind velocity components could give to one of them a preferred position against the other, and no reason exists $a$ priori for that. On the other hand, it has been reported that the Z-score standardization has been found to be less effective in several situations [29,30]. However, this is still controversial, and no golden rule exists yet for preferring one scaling procedure over the others.

\subsubsection{Clustering Algorithm and Software}

The algorithm we selected to carry out the clustering process was the hierarchical method of Ward with a Euclidean measure of distance [26,27,29]. The Ward's procedure for hierarchical clustering consists in forming groups of mutually exclusive subsets based on their similarity with respect to specified characteristics and accepting the union with which an optimal value of an objective function is associated [26]. Typically, this function is the error sums of squares, and the method is known as Ward's minimum variance method. This method can be defined and implemented recursively by a Lance-Williams algorithm [31]. The Lance-Williams recurrence formula gives the distance between a cluster $k$ and a cluster $(p q)$ formed by the fusion of two clusters ( $p$ and $q$ ) as

$$
d_{(p q) k}=A_{p} d_{p k}+A_{q} d_{q k}+B d_{p q}+C\left|d_{p k}-d_{q k}\right|
$$

where $d_{p q}$ is the distance between clusters $p$ and $q$, and $A_{p}, A_{q}, B$, and $C$ are parameters, which may depend on cluster sizes $n_{p}, n_{q}$, and $n_{k}$. For the Ward's method, these parameters are given by [32]:

$$
A_{p}=\left(\frac{n_{p}+n_{k}}{n_{p}+n_{q}+n_{k}}\right), A_{q}=\left(\frac{n_{q}+n_{k}}{n_{p}+n_{q}+n_{k}}\right), B=-\left(\frac{n_{k}}{n_{p}+n_{q}+n_{k}}\right), C=0
$$

The initial distances are calculated using a Euclidean metric, such as that expressed by Equation (1), thereafter distance is calculated with the Lance-Williams formula; and it will be referred to as the Ward's distance.

In practice, we carried out the cluster analysis using the software package DataLab [33]. This program was executed with the options of Ward's Method for Linkage Type, Euclidean for Distance Measure, and unscaled for Scaling of Data, in the configuration section.

\subsubsection{Dendrograms and Selection of the Number of Clusters}

In cluster analysis, an important aspect of the process is to define the number of clusters in which the set of data objects will be organized. The hierarchical clustering methods, however, provide a very limited guide to select this number. The only significant indicator refers to the distance at which objects are combined. A common way to view the progress of the cluster analysis is a dendrogram drawing. This is a diagram showing the levels of distance in which the merging of clusters occur. 
The dendrograms produced by DataLab for the seasonal periods suggest that the range of values of the Ward's distance for which the organization of the Mexico City wind states in six clusters occurs, indicates the beginning of organizations with less clusters but with more stability with respect to the increments of this similarity parameter. Therefore, we decided to study the case with six clusters of wind states. Figure 3 shows four examples of the dendrograms produced by DataLab for different seasonal periods and different years. Each dendrogram shows also a red dashed line that highlights the case of six clusters of wind states.
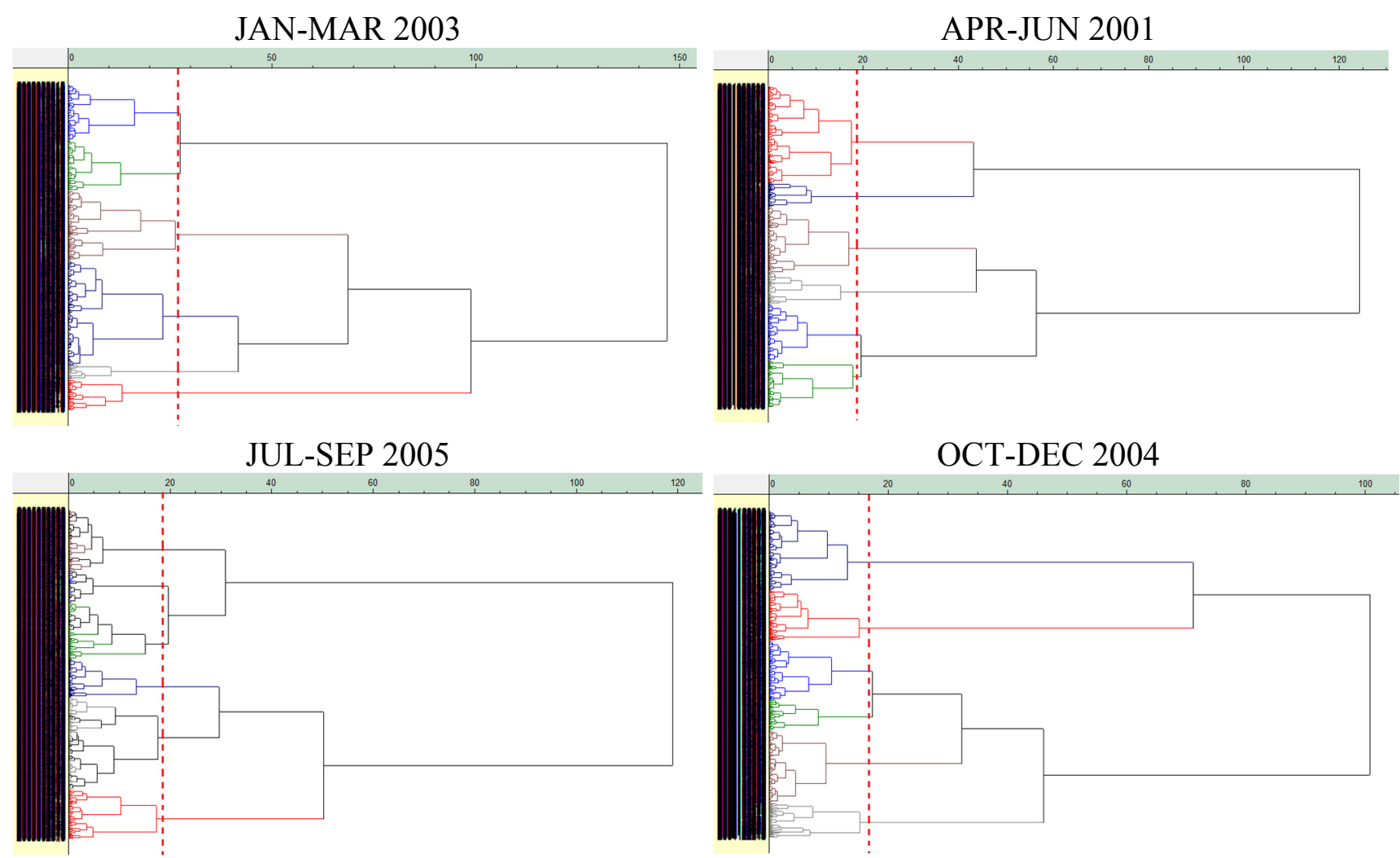

Figure 3. Examples of the dendrograms obtained with DataLab for the clustering of the Mexico City wind states. The x-axis in these figures corresponds to the Ward's distance.

\section{Results and Discussion}

From the standpoint of the 1-cell LWM, the Mexico City wind events of the period 2001-2006 are represented by the quartets $(u, v, \gamma, \omega)$ contained in the set E1C. This set of wind states expresses the temporal behavior of the wind state parameters which is shown in Figure 4. In Table 3, the mean, minimum, and maximum values are summed up for the state variables and wind speed. For wind speed, it was calculated first from the $u$ and $v$ values for each wind state $(u, v, \gamma, \omega)$. It must be stressed that the figures reported in Table 3 refer to the elements of the set $E_{1 C}$ of the model wind events produced by the 1-cell LWM. Nevertheless, these figures are in agreement with the records contained in the annual climatological reports (Informes Climatológicos 2001-2006) published by the atmospheric monitoring system of Mexico City [34], particularly with the measurements of the MERCED (MER) station, which is the closest one to the center of our spatial domain. 
Table 3. Basic statistics of the wind state parameters (2001-2006).

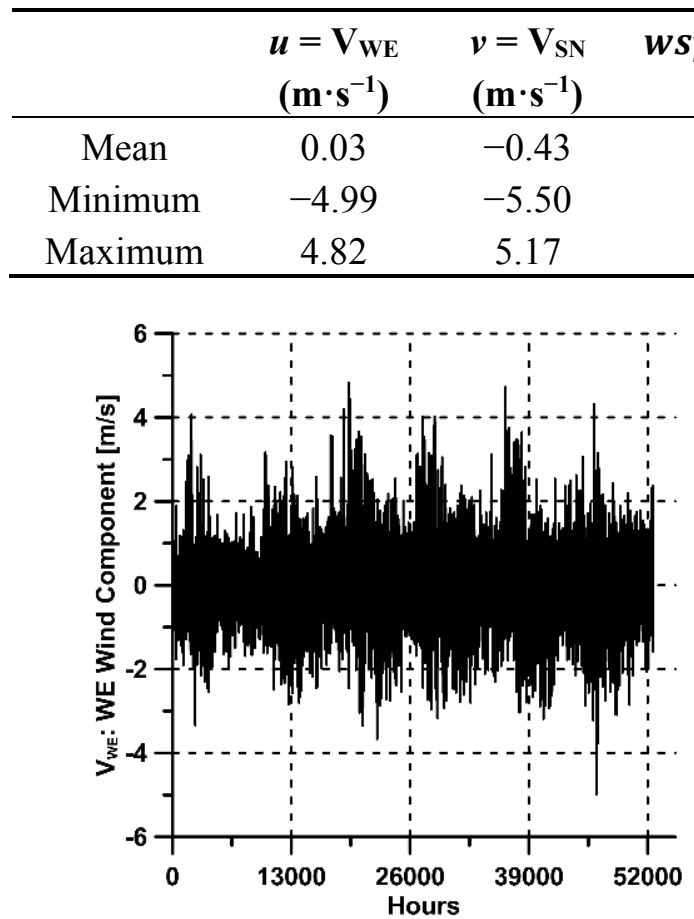

(a)

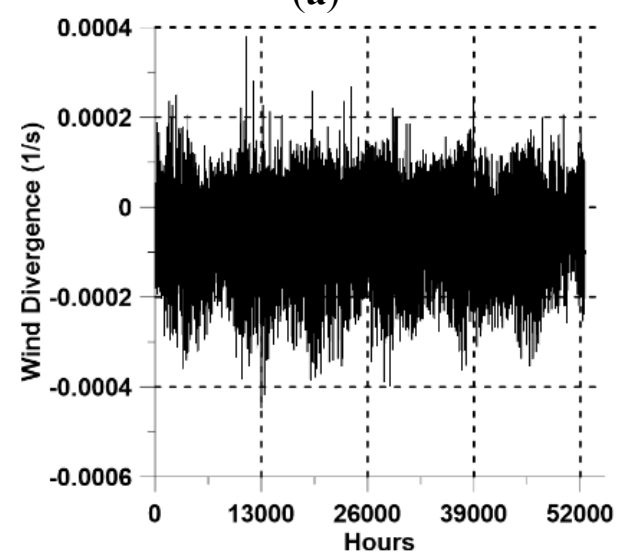

(c)

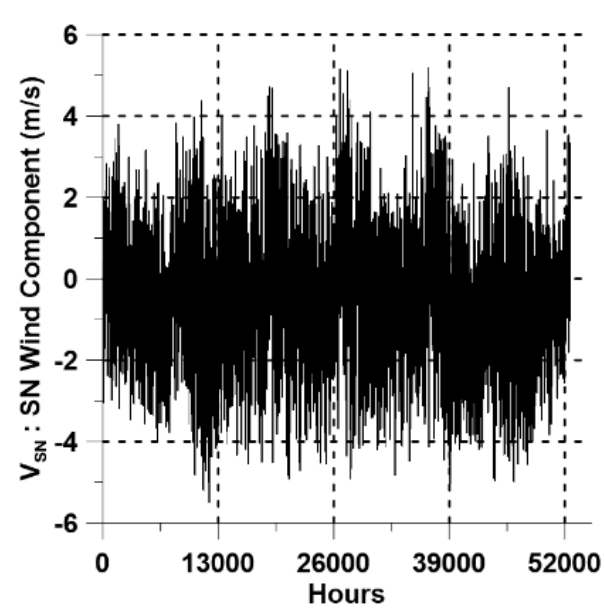

(b)

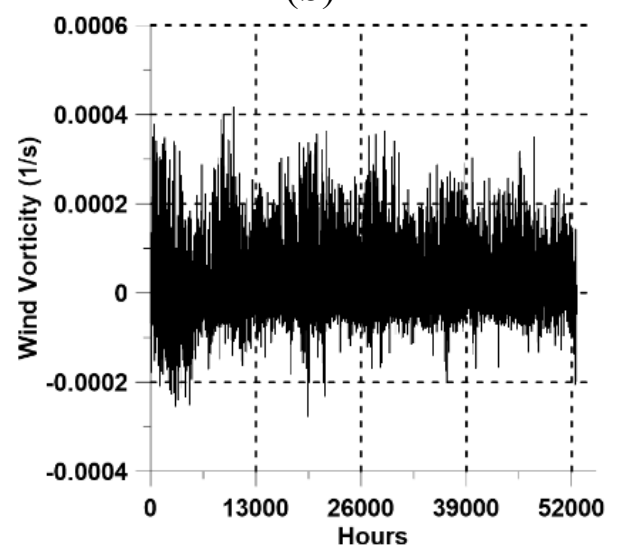

(d)

Figure 4. Temporal behavior of the Mexico City wind state parameters $(u, v, \gamma, \omega)$. Period 2001-2006. (a) West to east wind velocity component; (b) south to north wind velocity component; (c) wind divergence; (d) wind vorticity.

Figure 4 contains four panels with the graphs of the temporal behaviors of the wind velocity components west to east $(u)$ and south to north $(v)$, and of wind divergence $(\gamma)$ and wind vorticity $(\omega)$. In these graphs, we can observe other characteristics that the Mexico City wind events presented during the period 2001-2006 [25,35]:

(a) West-east wind velocity component $\left(u=V_{\mathrm{WE}}\right)$ was positive for $52 \%$ of the hourly wind states, indicating a slight dominance of winds with a westerly flow component.

(b) South-north wind velocity component $\left(v=V_{S N}\right)$ was negative for $66 \%$ of the hourly wind states period, indicating a clear dominance of winds with a northerly flow component. 
(c) In according to the Beaufort scale categories, $9 \%$ of the wind events were calms, $65 \%$ were light air, and $26 \%$ were light breeze.

(d) Wind divergence $\gamma$ was negative for $78 \%$ of the wind events, indicating that winds with convergent characteristics prevailed not only during the nighttime but also during $50 \%$ of daylight hours, when it should be expected that the flow induced by the urban heat island would be weakened by the turbulent mixing processes.

(e) Wind vorticity $\omega$ was positive during $61 \%$ of the wind events of the period, indicating a predominance of cyclonic winds. This fact, given the orographic features of the region, could be correlated with the predominance of winds with a northerly flow component $(66 \%)$; however, the argument should take into account all possible wind forcing.

On the other hand, the hourly distributions of population of the clusters of Mexico City wind states for the seasonal periods are shown in Figures 5-8. Each figure contains six panels, one for each year of the study period. The graph at each panel presents the temporal evolution of the population of the clusters associated with a given seasonal period of the given year. Values on the x-axis are integer numbers that indicate which $1 \mathrm{~h}$ average period is being considered (Mexico City local time, UTC-6h); so the hour of day $h$, in these graphs, is associated with the value of the cluster population that corresponds to the wind data averaged over the $1 \mathrm{~h}$ interval between $h$ and $h+1$. Population is expressed as a percentage relative to the number of wind states of the seasonal period. In all these graphs, the clusters are identified as G1, G2, G3, G4, G5, and G6, but no correspondence exists (necessarily) between equal labels of different graphs.
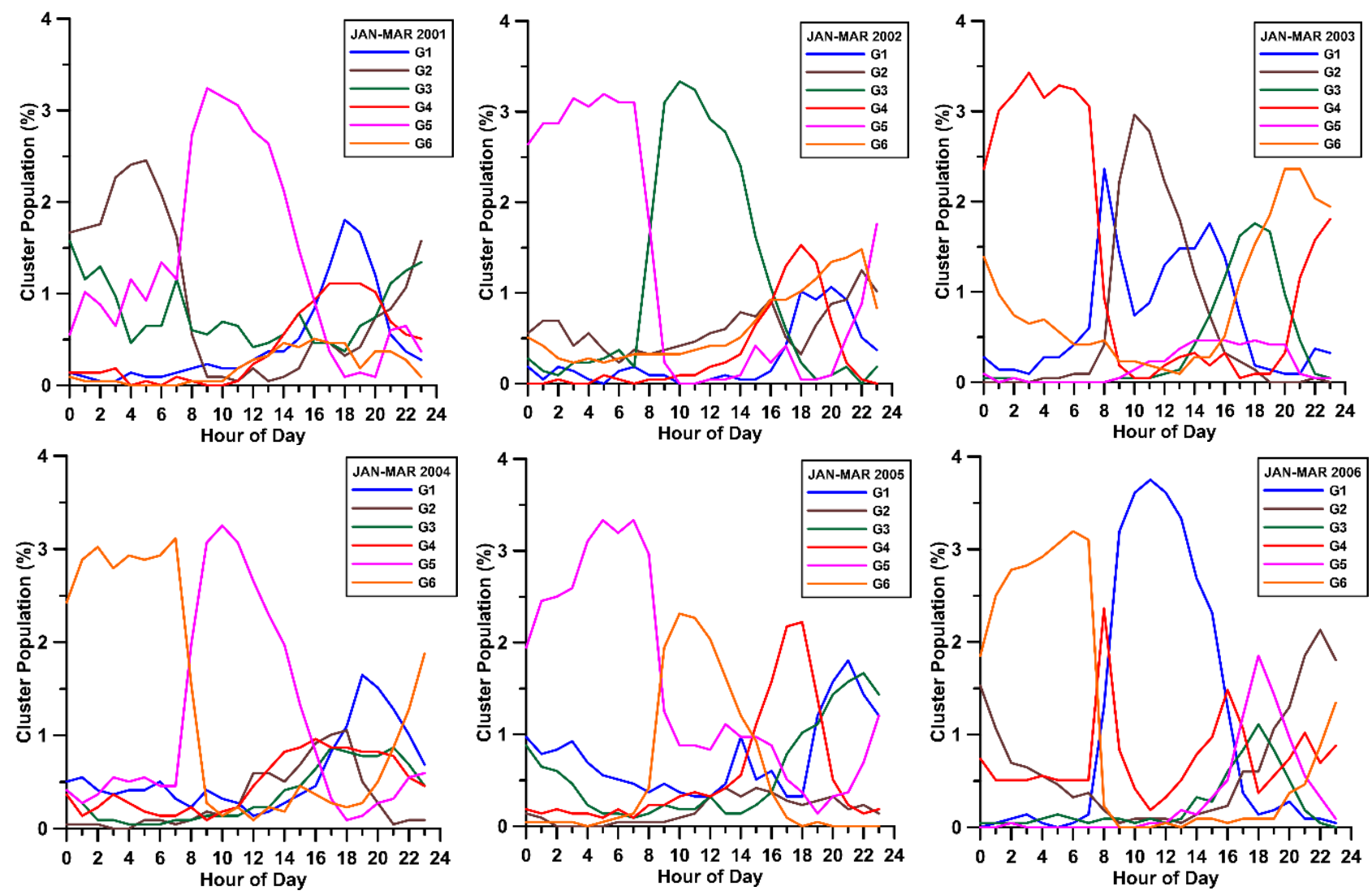

Figure 5. Winter populations of the Mexico City wind state clusters for the years 2001-2006. 

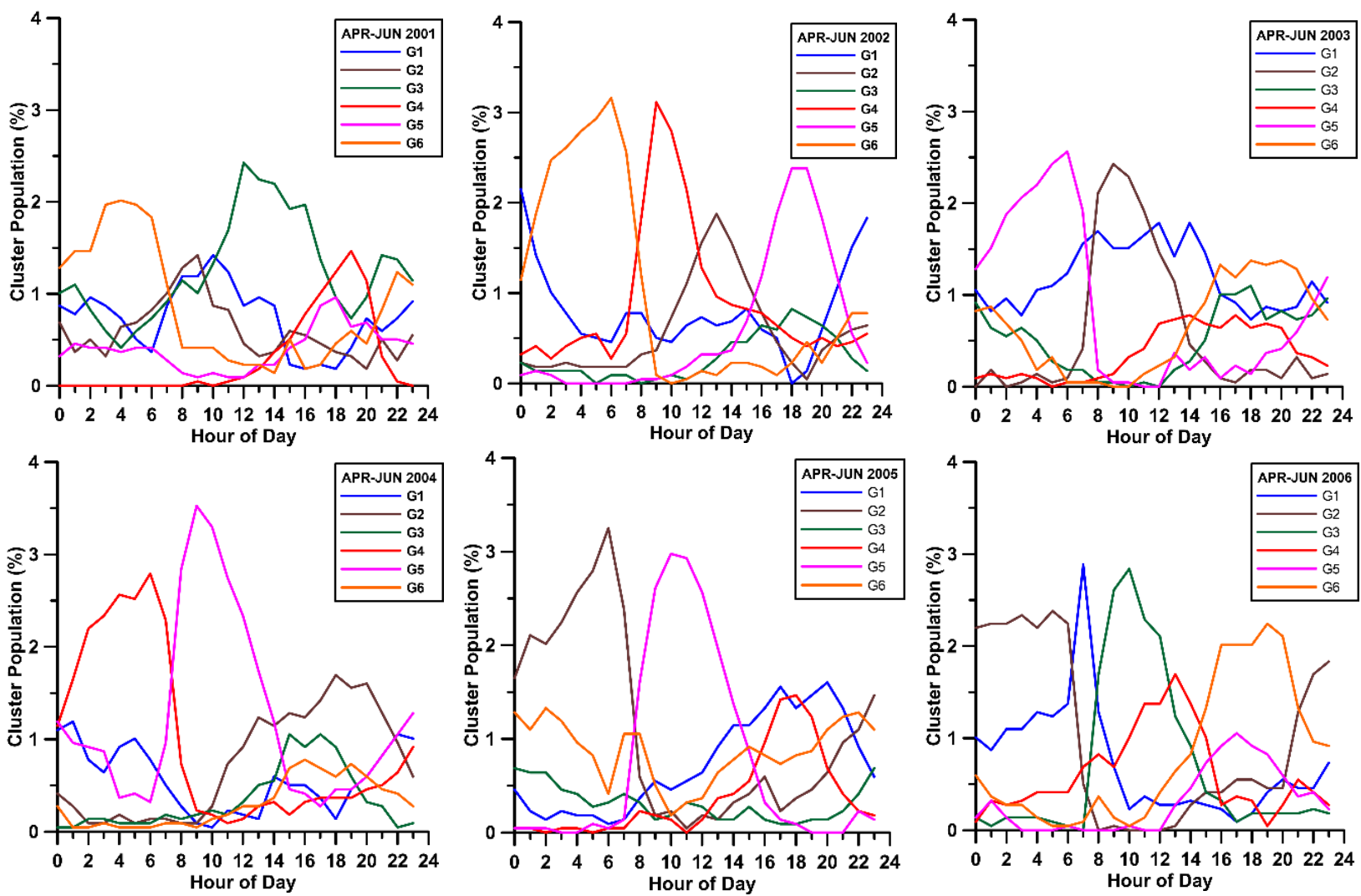

Figure 6. Spring populations of the Mexico City wind state clusters for the years 2001-2006.
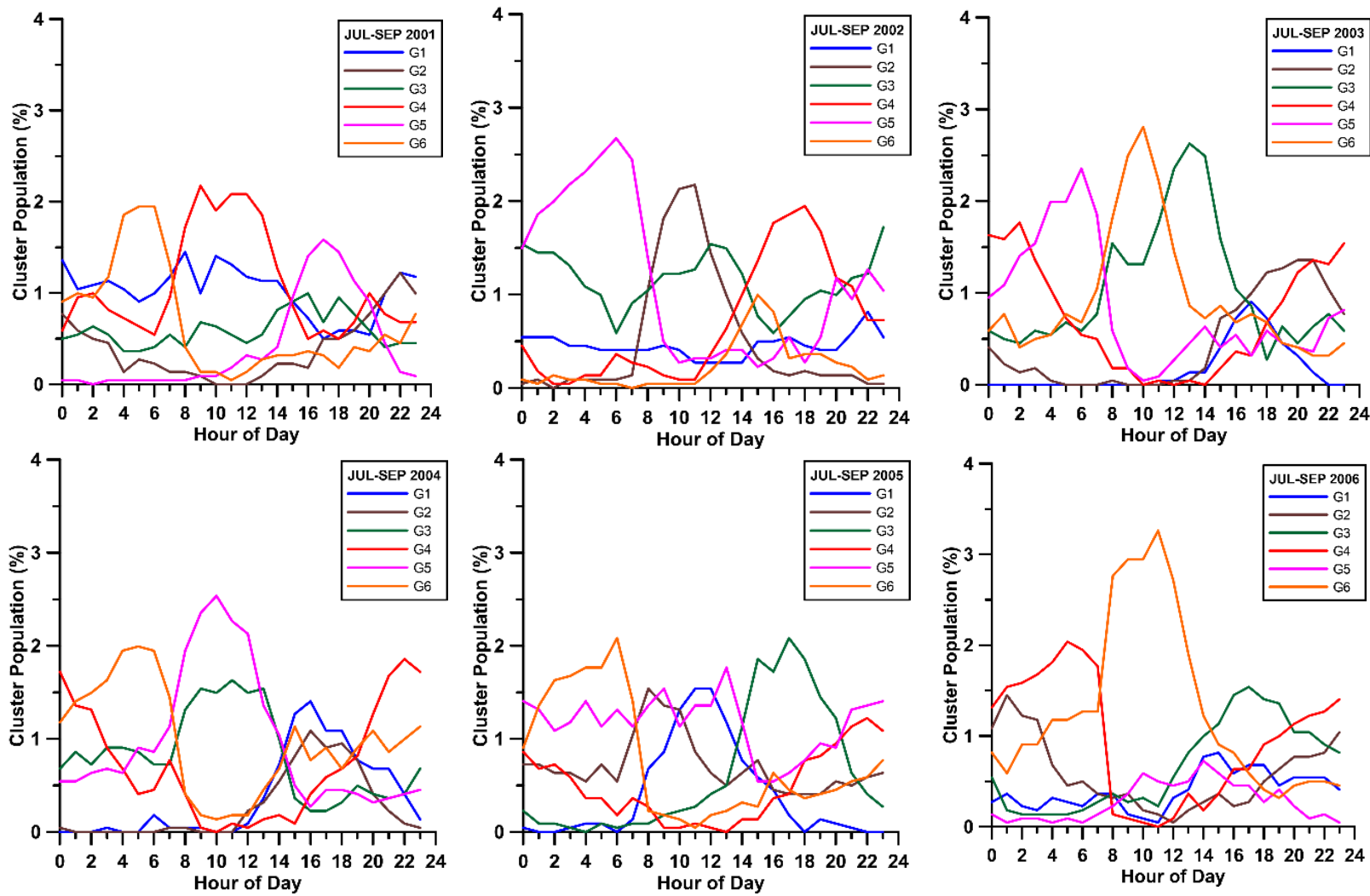

Figure 7. Summer populations of the Mexico City wind state clusters for the years 2001-2006. 

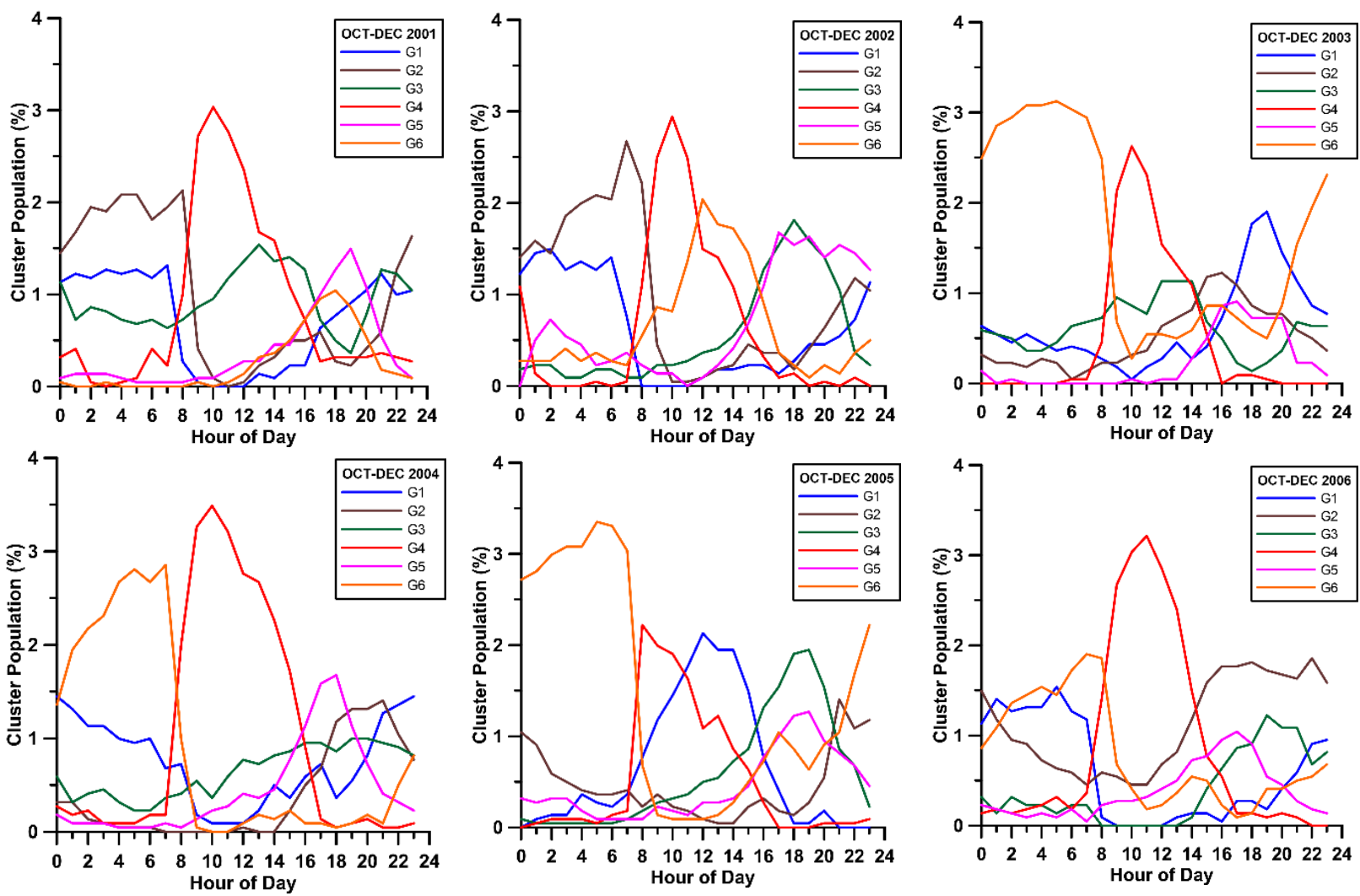

Figure 8. Autumn populations of the Mexico City wind state clusters for the years 2001-2006.

Comparison of these graphs makes evident several regularities which clearly suggest the existence of wind circulation patterns in the region. For example, with reference to Figure 5, for the winter season (JAN-MAR), the population trends of the clusters G5 of 2001, G3 of 2002, G2 of 2003, G5 of 2004, G6 of 2005, and G1 of 2006 are quite similar to each other; the population trends of these clusters start to grow from zero around hour 7, reach a maximum value around hour 10, and then start to decrease, dying around hour 18. However, these similarities by themselves not always are enough to identify wind circulation patterns. It may occur, in fact, that clusters with similar hourly population trends may comprise wind states with very different wind flow directions. For instance, the clusters G1 of 2005 and G6 of 2003 of the spring season (APR-JUN) have similar population trends, as it is shown in Figure 6 (both take place during afternoon with a maximum around the hour 18); however, the wind states contained in G1 of 2005 represent northerly winds, while the wind states of G6 of 2003 represent southerly winds. To surpass this ambiguity, we can resort to complementary classification criteria, such as the wind direction states associated with of the mean wind states of the clusters.

Each one of these clusters comprises a number of similar wind states that represent instances of a specific mode of wind circulation in the city; that is, each cluster constitutes, statistically, an instance of a wind circulation pattern in the region. A schematic view of the wind circulation mode that each cluster represents is provided by the mean-wind direction state (MWDS), which is defined by the number of the 4-cell model wind states comprised by the given cluster, through a vector averaging process of the wind velocities of corresponding cells. Figure 9 shows schematic illustrations of the MWDS's associated with the wind state clusters for each year and seasonal period. 


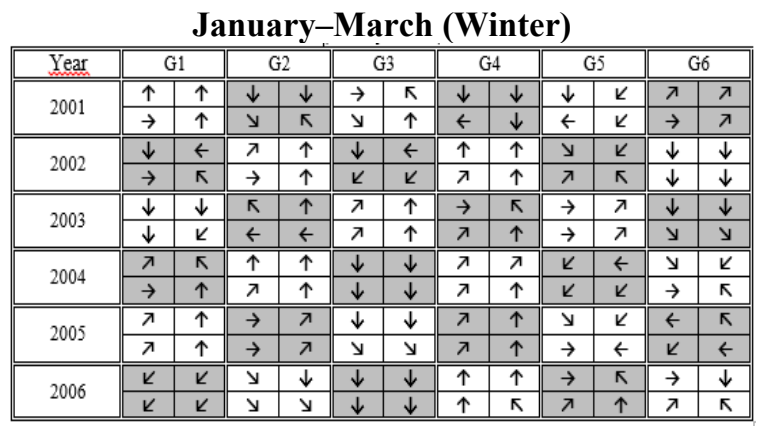

July-September (Summer)

\begin{tabular}{|c|c|c|c|c|c|c|c|c|c|c|c|c|}
\hline Y Year & \multicolumn{2}{|c|}{ G1 } & \multicolumn{2}{|c|}{ (G2 } & \multicolumn{2}{|c|}{$\overline{\text { G33 }}$} & \multicolumn{2}{|c|}{$\begin{array}{l}\mathrm{G} 4 \\
\end{array}$} & \multicolumn{2}{|c|}{ G5 } & \multicolumn{2}{|c|}{ "G6 } \\
\hline \multirow{2}{*}{2001} & $\bar{\downarrow} \downarrow$ & $\bar{\downarrow} \downarrow$ & $\overline{\nu \downarrow}$ & $\bar{\downarrow} \downarrow$ & $\overline{\bar{K}}$ & $\bar{\pi} \pi$ & $y$ & $\downarrow$ & $\overline{\nu \downarrow}$ & $\downarrow$ & $\overline{\nu \downarrow}$ & $\downarrow$ \\
\hline & $\downarrow$ & $\downarrow$ & $y$ & k & $\uparrow$ & $\kappa$ & K & $\downarrow$ & $\downarrow$ & $\downarrow$ & $\pi$ & $\leftarrow$ \\
\hline \multirow{2}{*}{2002} & $\bar{c} \uparrow$ & $\pi$ & $\overline{\nu \downarrow}$ & $\bar{k}$ & $\bar{\nu}$ & $\overline{\nu \downarrow}$ & $\bar{\nu}$ & k & $\downarrow$ & k & 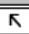 & $\bar{\kappa}$ \\
\hline & $\pi$ & $\pi$ & $K$ & $k$ & $\downarrow$ & $y$ & $\downarrow$ & $k$ & $y$ & $\pi$ & $\uparrow$ & $\kappa$ \\
\hline \multirow{2}{*}{2003} & $\bar{\downarrow} \downarrow$ & K & $\bar{~} \downarrow$ & $\bar{k}$ & $\downarrow$ & k & ע & $\downarrow$ & $y$ & V & $\bar{L}$ & $\bar{~} \uparrow$ \\
\hline & $\downarrow$ & $\downarrow$ & $y$ & $k$ & $\downarrow$ & $\downarrow$ & $y$ & $\rightarrow$ & $\rightarrow$ & $\pi$ & $k$ & $\pi$ \\
\hline \multirow{2}{*}{2004} & $\downarrow$ & K & $\bar{\nu}$ & $\bar{\nu}$ & $\bar{\nu}$ & $\downarrow$ & ע & $\downarrow$ & $\bar{\nu}$ & $\underline{k}$ & $y$ & $\bar{k}$ \\
\hline & $\downarrow$ & $\leftarrow$ & $\downarrow$ & $\downarrow$ & $\downarrow$ & $y$ & $y$ & $\rightarrow$ & k & $\leftarrow$ & $\pi$ & $\kappa$ \\
\hline \multirow{2}{*}{2005} & k & k & $\pi$ & $\pi$ & $\downarrow$ & $\downarrow$ & $\downarrow$ & $\downarrow$ & $\downarrow$ & $\downarrow$ & $y$ & $k$ \\
\hline & $k$ & $k$ & $\leftarrow$ & $\pi$ & $\downarrow$ & $k$ & $y$ & $y$ & $\downarrow$ & $\downarrow$ & $\rightarrow$ & $\kappa$ \\
\hline \multirow{2}{*}{2006} & $\bar{\downarrow} \downarrow$ & $\bar{k}$ & $\downarrow$ & $\downarrow$ & $\downarrow$ & $\downarrow$ & $y$ & $\bar{y}$ & $\bar{\pi} \bar{\kappa}$ & $\bar{\pi}$ & $\downarrow$ & $\bar{\nu}$ \\
\hline & $\rightarrow$ & $\pi$ & $y$ & $y$ & $\downarrow$ & $\downarrow$ & $\rightarrow$ & $\uparrow$ & $\pi$ & $\kappa$ & $\downarrow$ & $k$ \\
\hline
\end{tabular}

April-June (Spring)

\begin{tabular}{|c|c|c|c|c|c|c|c|c|c|c|c|c|}
\hline Year & \multicolumn{2}{|c|}{ G1 } & \multicolumn{2}{|c|}{$\mathrm{G} 2$} & \multicolumn{2}{|c|}{ G3 } & \multicolumn{2}{|c|}{$\mathrm{G} 4$} & \multicolumn{2}{|c|}{ G5 } & \multicolumn{2}{|c|}{ G6 } \\
\hline \multirow{2}{*}{2001} & $\rightarrow$ & $y$ & $\pi$ & $\pi$ & ע & $\downarrow$ & $\downarrow$ & $k$ & $\bar{\pi}$ & $\pi$ & $\downarrow$ & $\downarrow$ \\
\hline & $\leftarrow$ & $\rightarrow$ & $\rightarrow$ & $\uparrow$ & $\leftarrow$ & $k$ & $\leftarrow$ & $k$ & $\rightarrow$ & $\uparrow$ & y & $\pi$ \\
\hline \multirow{2}{*}{2002} & $\downarrow$ & $\downarrow$ & $\downarrow$ & $\downarrow$ & $\downarrow$ & $\leftarrow$ & $\uparrow$ & $\uparrow$ & $\downarrow$ & $\downarrow$ & $\bar{y}$ & $\bar{k}$ \\
\hline & $\downarrow$ & ע & $\downarrow$ & $\downarrow$ & $\rightarrow$ & $\pi$ & $k$ & $\uparrow$ & $\downarrow$ & $\downarrow$ & $\pi$ & $\kappa$ \\
\hline \multirow{2}{*}{2003} & $y$ & $\downarrow$ & $\leftarrow$ & $\leftarrow$ & $\downarrow$ & $k$ & $\downarrow$ & $\downarrow$ & $\rightarrow$ & K & $\pi$ & $\uparrow$ \\
\hline & ע & ע & $k$ & $\leftarrow$ & ע & $\downarrow$ & $\downarrow$ & $\downarrow$ & $\rightarrow$ & $\uparrow$ & $\pi$ & $\uparrow$ \\
\hline \multirow{2}{*}{2004} & $\rightarrow$ & $\pi$ & $\downarrow$ & $k$ & $\bar{\pi}$ & $\pi$ & $\bar{y}$ & $\downarrow$ & $\downarrow$ & $\downarrow$ & $\pi$ & $\rightarrow$ \\
\hline & $\pi$ & $\uparrow$ & $\downarrow$ & $k$ & $\uparrow$ & $\uparrow$ & $\rightarrow$ & $\pi$ & $\downarrow$ & $\downarrow$ & $\pi$ & $\pi$ \\
\hline \multirow{2}{*}{2005} & $\downarrow$ & $\downarrow$ & $y$ & $\downarrow$ & $\bar{y}$ & $\downarrow$ & $\pi$ & $\pi$ & $K$ & $k$ & $\pi$ & $\pi$ \\
\hline & $\downarrow$ & $\downarrow$ & $\rightarrow$ & $\leftarrow$ & ע & ע & $\pi$ & $\uparrow$ & $K$ & $k$ & $\pi$ & $\uparrow$ \\
\hline \multirow{2}{*}{2006} & $y$ & $\downarrow$ & y & $\downarrow$ & $\underline{k}$ & $k$ & $\downarrow$ & $\downarrow$ & $\uparrow$ & $\uparrow$ & $\downarrow$ & $\downarrow$ \\
\hline & $y$ & $\leftarrow$ & $\rightarrow$ & $\uparrow$ & k & $k$ & $\downarrow$ & $k$ & $\pi$ & $\uparrow$ & $\downarrow$ & \\
\hline
\end{tabular}

October-December (Autumn)

\begin{tabular}{|c|c|c|c|c|c|c|c|c|c|c|c|c|}
\hline Year & \multicolumn{2}{|c|}{ G1 } & \multicolumn{2}{|c|}{$\mathrm{G} 2$} & \multicolumn{2}{|c|}{ G3 } & \multicolumn{2}{|c|}{ G4 } & \multicolumn{2}{|c|}{ G5 } & \multicolumn{2}{|c|}{ G6 } \\
\hline \multirow{2}{*}{2001} & $\forall$ & $k$ & ע & $\downarrow$ & $\downarrow$ & $\downarrow$ & $\kappa$ & $\kappa$ & $\downarrow$ & $\downarrow$ & $\uparrow$ & $\pi$ \\
\hline & $\rightarrow$ & $\kappa$ & $\leftarrow$ & $\leftarrow$ & $k$ & $\downarrow$ & $\leftarrow$ & $\leftarrow$ & $K$ & $\downarrow$ & $\uparrow$ & $\uparrow$ \\
\hline \multirow{2}{*}{2002} & $\rightarrow$ & $\downarrow$ & $\rightarrow$ & $k$ & $\uparrow$ & $\kappa$ & $k$ & $k$ & $\downarrow$ & $\downarrow$ & $\downarrow$ & $\downarrow$ \\
\hline & $\pi$ & $\uparrow$ & $\pi$ & $\kappa$ & $\pi$ & $\kappa$ & $K$ & $\leftarrow$ & $\downarrow$ & $\downarrow$ & $\downarrow$ & $\downarrow$ \\
\hline \multirow{2}{*}{2003} & $\downarrow$ & $K$ & $\downarrow$ & $\downarrow$ & $y$ & $\downarrow$ & $\leftarrow$ & $\kappa$ & $\Sigma$ & $\kappa$ & $\rightarrow$ & $K$ \\
\hline & $\forall$ & $\downarrow$ & $\downarrow$ & $\downarrow$ & $\downarrow$ & y & $K$ & $\leftarrow$ & $\pi$ & $\uparrow$ & $\pi$ & $\kappa$ \\
\hline \multirow{2}{*}{2004} & $y$ & $\downarrow$ & $y$ & $\downarrow$ & $\downarrow$ & $\downarrow$ & $K$ & $k$ & $\uparrow$ & $\uparrow$ & $\rightarrow$ & $\downarrow$ \\
\hline & $\rightarrow$ & $\uparrow$ & ע & $\pi$ & $\downarrow$ & $\downarrow$ & $k$ & $k$ & $\pi$ & $\kappa$ & $\pi$ & $\leftarrow$ \\
\hline \multirow{2}{*}{2005} & $\downarrow$ & $\downarrow$ & ע & $\downarrow$ & $\downarrow$ & $\downarrow$ & $\leftarrow$ & $\leftarrow$ & $\pi$ & $\uparrow$ & $y$ & $\downarrow$ \\
\hline & $\downarrow$ & $\downarrow$ & $\forall$ & ע & $\downarrow$ & $\downarrow$ & $\underline{\underline{k}}$ & $\underline{k}$ & $\pi$ & $\uparrow$ & $\rightarrow$ & 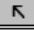 \\
\hline \multirow{2}{*}{2006} & $\rightarrow$ & $\rightarrow$ & $\downarrow$ & $\downarrow$ & ע & $\pi$ & $k$ & $\kappa$ & $\uparrow$ & $\uparrow$ & $y$ & $\pi$ \\
\hline & $\pi$ & $\kappa$ & y & $\downarrow$ & $\rightarrow$ & $\uparrow$ & $k$ & K & $\uparrow$ & $\uparrow$ & ע & $\kappa$ \\
\hline
\end{tabular}

Figure 9. Mean-wind direction states associated to the wind state clusters for the seasonal periods.

In order to identify the wind circulation patterns, for each seasonal period we organized its 36 wind state clusters in accordance with the similarities in both their hourly population trends and mean wind direction states. Figure 10 summarizes the results in a matrix arrangement of 32 graphs. Each row corresponds to one specific wind circulation pattern, while each column represents one specific seasonal period. Each graph includes a maximum of six plots (one for each year) that describe the hourly distributions of the cluster populations for the same wind circulation pattern. The mean-wind direction states of the clusters are shown at the bottom of the graphs. Seven wind circulation patterns (WP1, WP2, WP3, WP4, WP5, WP6 and WP7) were identified in the study period. These patterns were detected throughout each year, although a seasonal dependence is observed. On average, the maximum cluster populations decrease from winter to spring, and from spring to summer, but increase again from summer to autumn. WP5 exhibited a different behavior, and was observed only during winter and spring.

WP1

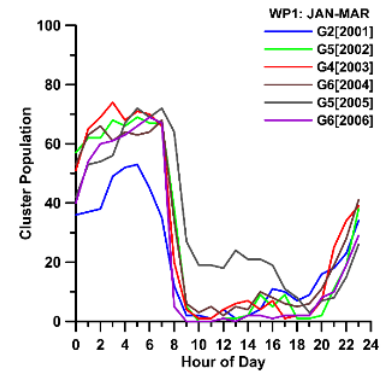

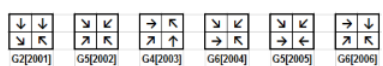

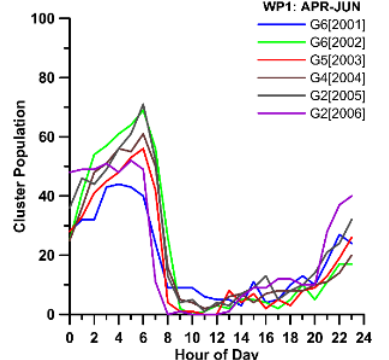

$\begin{aligned} & 10 \\ & \text { Hour of Day }\end{aligned}$
Hor

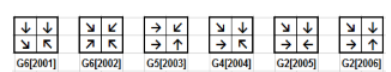

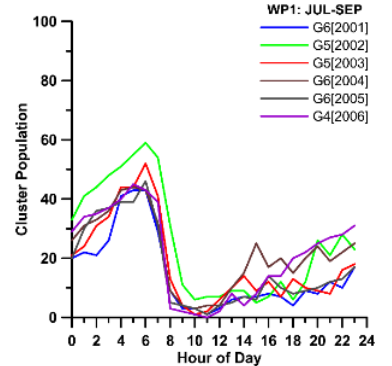

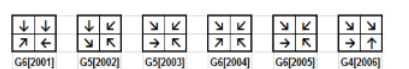

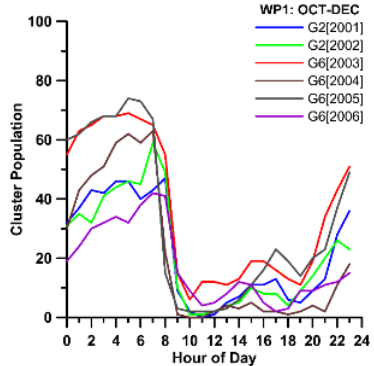

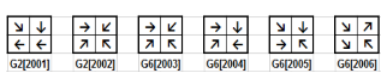

Figure 10. Cont. 


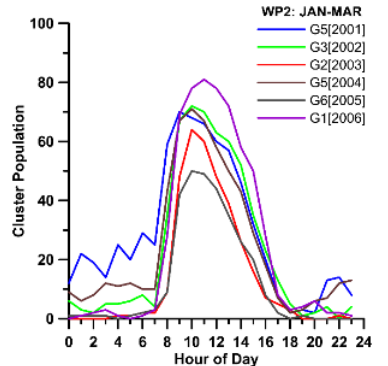

圈圈国国国国国国

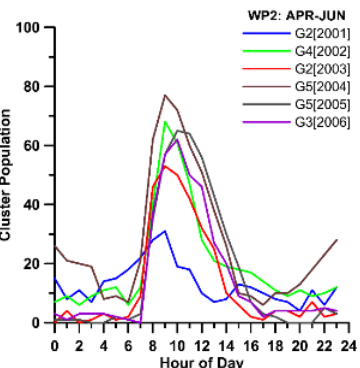

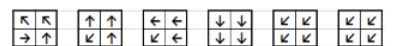
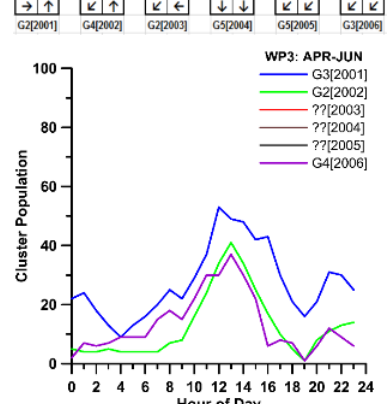
101214
Hour of Day
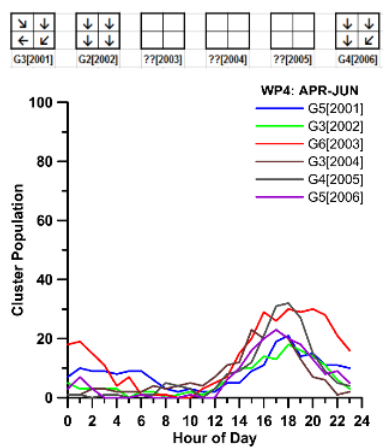

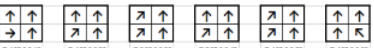

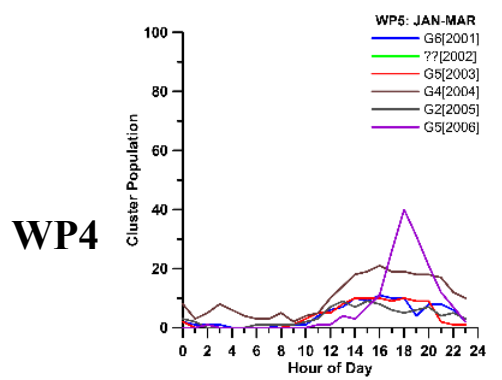

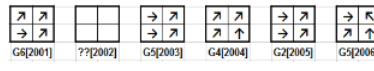

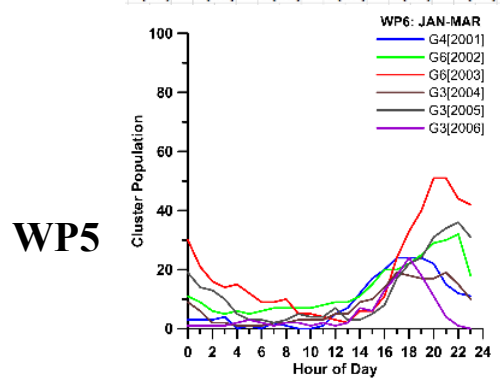

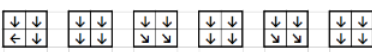
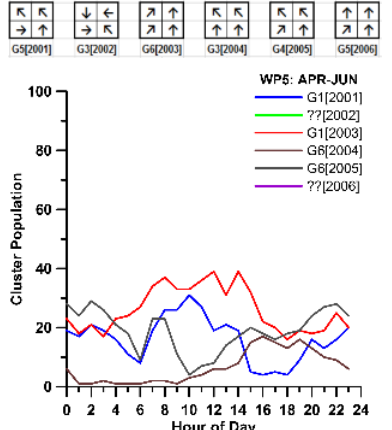

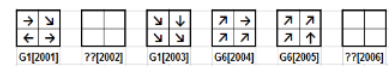

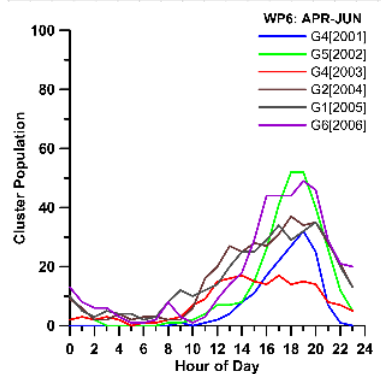

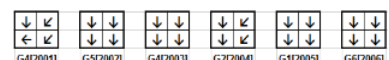
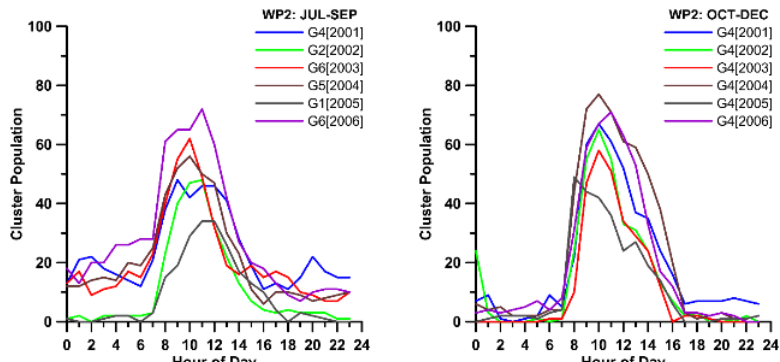

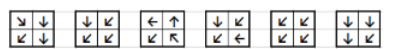

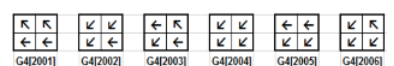
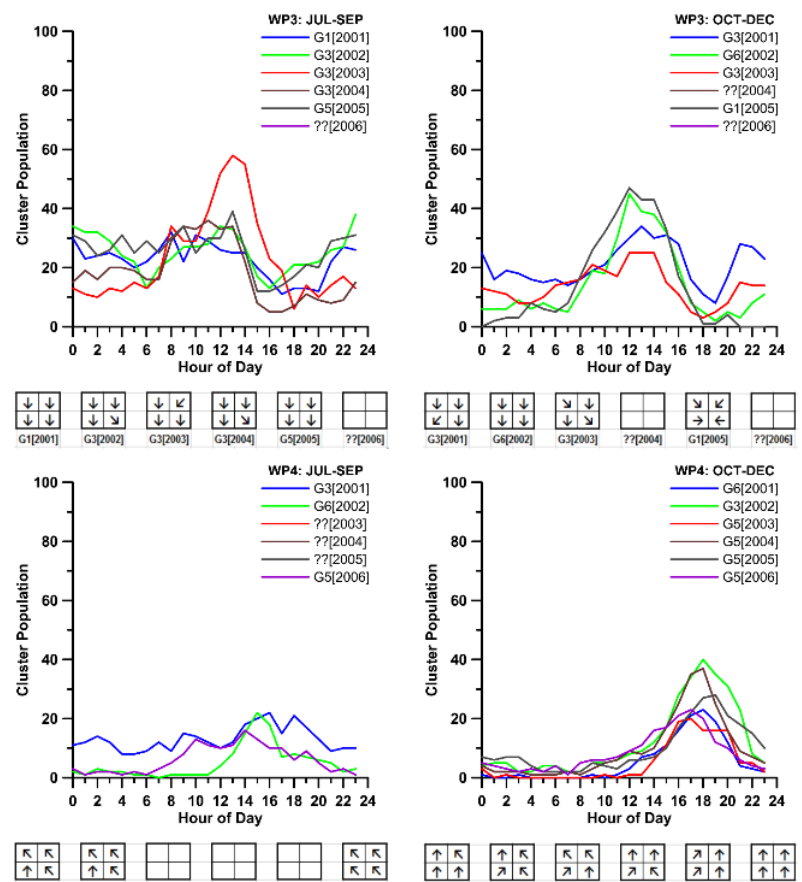

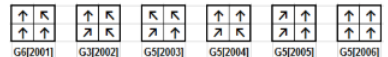
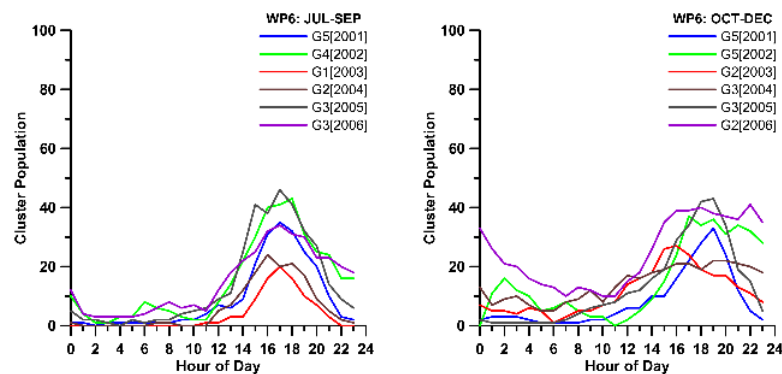

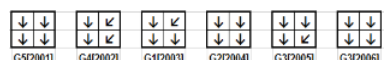

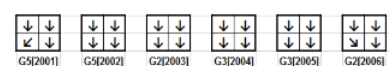

Figure 10. Cont. 

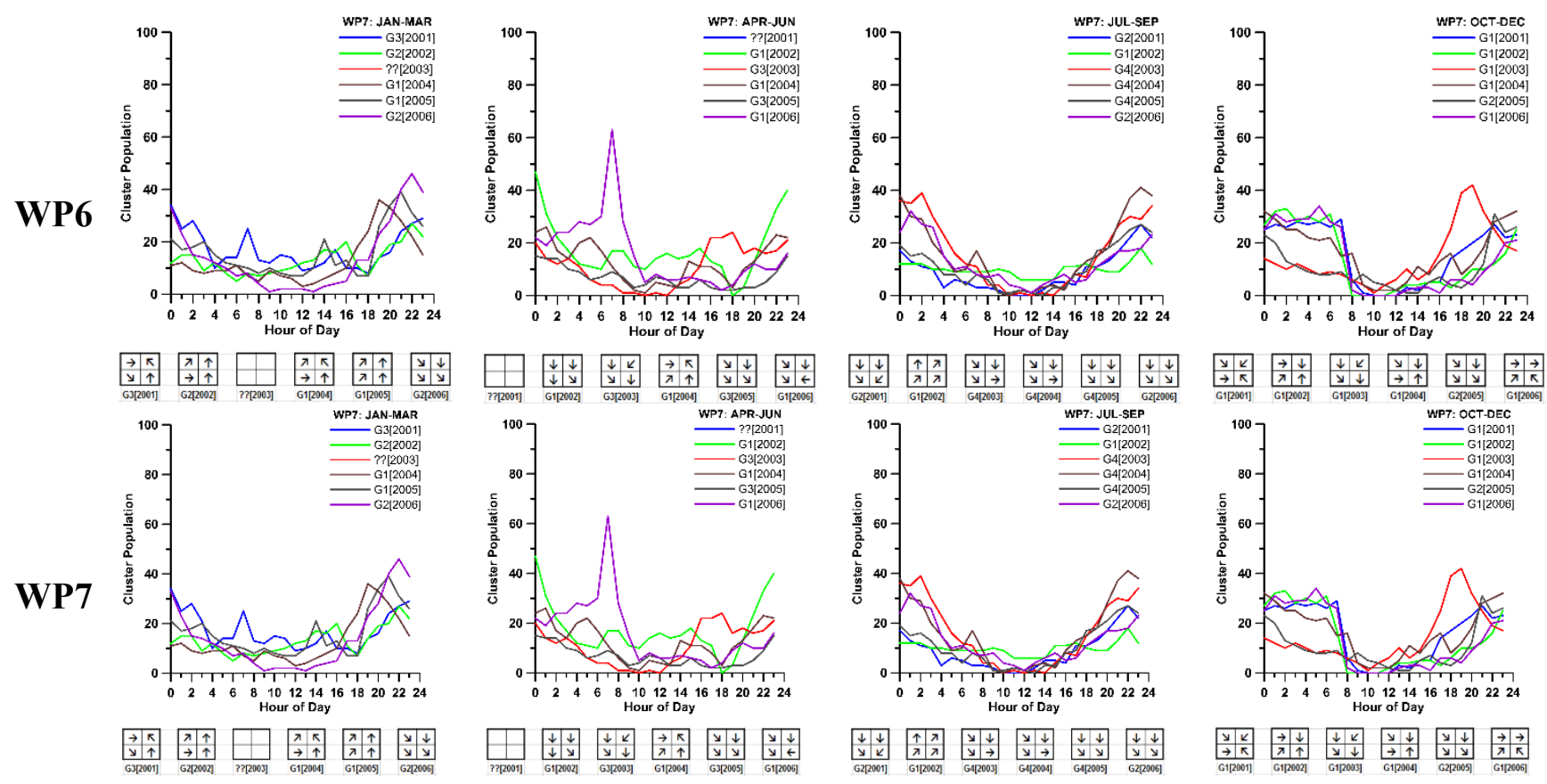

Figure 10. Wind circulation patterns of Mexico City that were identified in the period 2001-2006. Question marks (??) in the graph legends indicate that no cluster was found for the seasonal periods and years specified.

In Figure 11, the annual averages of the hourly population trends of the wind circulation patterns are shown. Table 4 summarizes the velocity components, speed and direction, and direction state of the mean wind associated with each wind circulation pattern. Table 5 summarizes, on average, the seasonal and annual occurrence frequencies of these patterns. Table 6 sums up the annual averages of the relative occurrence frequencies of the wind state parameters for each pattern.

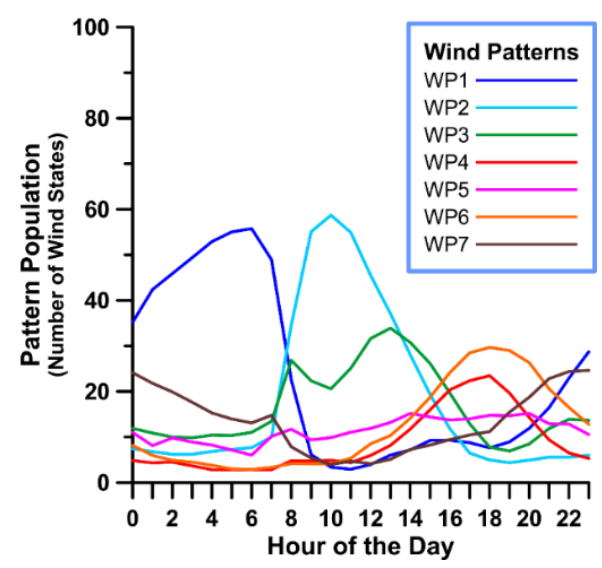

Figure 11. Annual averages of the hourly population trends of the Mexico City wind circulation patterns. 
Table 4. Velocity components $(u, v)$, speed (wsp) and direction (wdr), and direction state of the mean wind associated with each wind circulation pattern.

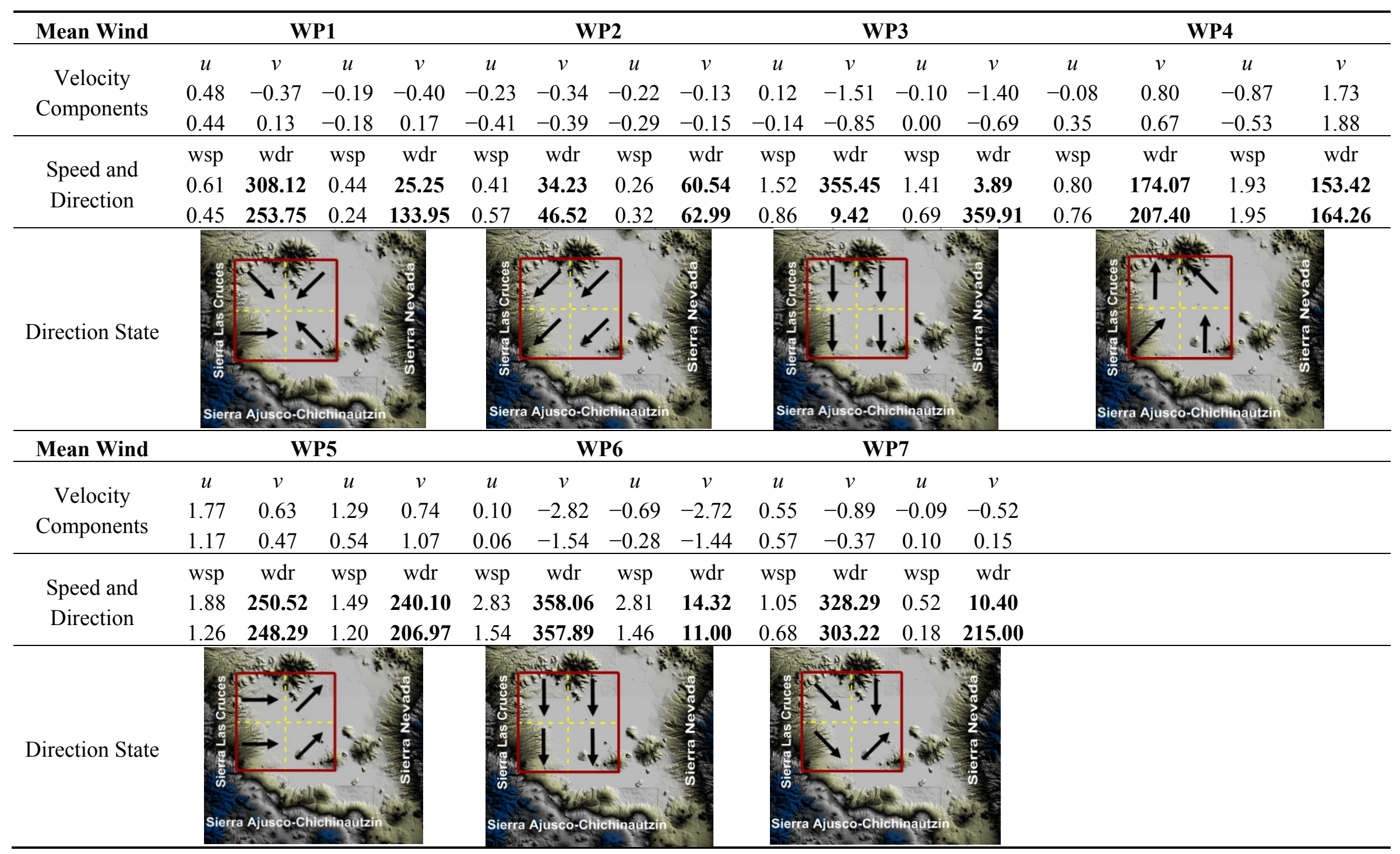


Table 5. Average occurrence frequencies of the Mexico City wind circulation patterns. (2001-2006).

\begin{tabular}{|c|c|c|c|c|c|c|}
\hline \multirow{2}{*}{$\begin{array}{l}\text { Wind } \\
\text { Pattern }\end{array}$} & \multirow[b]{2}{*}{ Description } & \multicolumn{4}{|c|}{ Average Seasonal Frequencies (\%) } & \multirow{2}{*}{$\begin{array}{l}\text { Average Annual } \\
\text { Frequency (\%) }\end{array}$} \\
\hline & & $\begin{array}{l}\text { Jan-Mar } \\
\text { (Winter) }\end{array}$ & $\begin{array}{c}\text { Apr-Jun } \\
\text { (Spring) }\end{array}$ & $\begin{array}{c}\text { Jul-Sep } \\
\text { (Summer) }\end{array}$ & $\begin{array}{c}\text { Oct-Dec } \\
\text { (Autumn) }\end{array}$ & \\
\hline WP1 & Early morning katabatic winds & 30 & 24 & 21 & 27 & 26 \\
\hline WP2 & Northeasterly and Easterly winds & 23 & 19 & 21 & 18 & 20 \\
\hline WP3 & Midday northerly winds & 3 & 10 & 21 & 12 & 11 \\
\hline WP4 & Afternoon southerly winds. & 11 & 9 & 4 & 9 & 9 \\
\hline WP5 & Westerly winds. & 5 & 12 & 0 & 0 & 4 \\
\hline WP6 & Afternoon northerly winds. & 12 & 14 & 11 & 16 & 13 \\
\hline \multirow[t]{2}{*}{ WP7 } & Midnight katabatic winds. & 14 & 12 & 14 & 15 & 14 \\
\hline & TOTAL & 99 & 100 & 92 & 97 & 97 \\
\hline
\end{tabular}

Table 6. Annual averages of the relative occurrence frequencies of the wind state parameters for the different wind circulation patterns. (2001-2006).

\begin{tabular}{ccccccccc}
\hline \multirow{2}{*}{ Wind State Parameters } & \multicolumn{7}{c}{ Relative Occurrence Frequency (Annual Average) [\%] } \\
\cline { 3 - 9 } & WP1 & WP2 & WP3 & WP4 & WP5 & WP6 & WP7 \\
\hline \multirow{4}{*}{ WSP } & Calm & 22 & 7 & 2 & 2 & 4 & 0 & 6 \\
& Light air & 73 & 82 & 48 & 35 & 29 & 12 & 56 \\
& Light breeze & 5 & 11 & 50 & 58 & 55 & 76 & 37 \\
& Gentle breeze & 0 & 0 & 0 & 4 & 12 & 12 & 0 \\
\hline \multirow{6}{*}{ WDR } & N & 19 & 20 & 64 & 1 & 8 & 69 & 25 \\
& NE & 11 & 31 & 15 & 3 & 4 & 17 & 6 \\
& $\mathrm{E}$ & 6 & 21 & 2 & 8 & 2 & 1 & 3 \\
& $\mathrm{SE}$ & 5 & 11 & 1 & 30 & 4 & 0 & 6 \\
& $\mathrm{~S}$ & 8 & 5 & 0 & 43 & 9 & 0 & 12 \\
& $\mathrm{SW}$ & 17 & 3 & 0 & 12 & 43 & 0 & 12 \\
\hline WDIV & $\mathrm{W}$ & 18 & 3 & 2 & 2 & 24 & 1 & 9 \\
\hline WVOR & $\mathrm{NW}$ & 17 & 6 & 16 & 1 & 7 & 12 & 27 \\
\hline
\end{tabular}

$\mathrm{WSP}=$ wind speed; $\mathrm{WDR}=$ wind direction; $\mathrm{WDIV}=$ wind divergence; $\mathrm{WVOR}=$ wind vortivity.

The most frequently observed wind circulation patterns of Mexico City were WP1 (early morning katabatic winds) and WP2 (northeasterly and easterly winds) with occurrence probabilities of $26 \%$ and $20 \%$, respectively. WP1 comprises, at least, the downslope wind events driven by the mountain-valley system of Mexico City. WP2 comprises surface wind events related with the trade winds. Other important patterns were WP7 (midnight katabatic winds), WP6 (afternoon northerly winds) and WP3 (midday northerly winds) with occurrence probabilities of $14 \%, 13 \%$, and $11 \%$, respectively.

A brief description of each one of the seven wind circulation patterns is provided in the following paragraphs. The patterns were enumerated following the order of their appearance during the day. Mexico City local time (UTC-6h) was considered. 
WP1: Early Morning Katabatic Winds. This is the wind pattern with the highest annual frequency in the study period (26\%). It was observed systematically throughout the year for each year, especially during the dry seasons, winter (30\%) and autumn (27\%). On annual average, $73 \%$ of the wind states in this pattern represent weak winds (light air, in the Beaufort scale), converging towards the city downtown very frequently $(\gamma<0,98 \%)$, blowing mainly from north and the west side cardinal sectors, with slight predominance of anticyclonic vorticity $(\omega<0,56 \%)$. The wind states in this pattern started to develop around hour 18, increasing the cluster population which reached and maintained its highest values from midnight to sunrise, and then suddenly decreased, almost dying around the hour 8 (Figure 11). Their wind direction states suggest downslope winds from the surrounding mountains, converging towards Mexico City basin due to gravitational effect; however, this pattern is reinforced by the urban heat island effect, as it has been already described by Jauregui [6] and Klaus et al. [36].

WP2: Northeasterly and Easterly Winds. The annual average frequency of this pattern was $20 \%$. It was observed systematically throughout the year for each year, especially during winter (23\%) and summer (21\%). Its wind states represent light air (82\%), divergent $(\gamma>0,67 \%)$ winds blowing from NE (31\%) and E (21\%) in almost all the city quadrants; no dominant vorticity sign was observed. The wind states occur mainly during the daylight hours, starting to develop at sunrise (around hour 7). Their cluster populations reached maximum values close to noon and died out between the hours 17 and 18. The occurrence probabilities of this pattern suggest that it is probably correlated with the Caribbean Low Level Jet. The Caribbean wind is predominantly zonal with an easterly direction year-round. At $925 \mathrm{hPa}$, the zonal Caribbean winds fluctuate in strength throughout the year, being stronger in July and February and weaker in October and May, which is indicative of a semiannual cycle [37,38].

WP3: Midday Northerly Winds. This wind pattern occurred with an annual average frequency of $11 \%$. It was observed especially during summer (21\%), but it was practically absent during winter (3\%). On average, the wind states mainly represent light breeze and light air winds, convergent $(\gamma<0$, $70 \%)$ and cyclonic $(\omega>0,60 \%)$, blowing from the north sectors in almost all the city quadrants. The wind state cluster populations develop from sunrise, reaching their maximum values around midday, and dying at sunset, around the hour 18.

WP4: Afternoon Southerly Winds. This wind pattern occurred with an annual average frequency of $9 \%$. It was observed especially during winter (11\%), but it was practically absent during summer (4\%). The wind states represent (on average) light breeze winds, convergent $(\gamma<0,84 \%)$ and very frequently cyclonic $(\omega>0,93 \%)$, blowing from the south sectors in all the city quadrants, guided by a ventilation channel $\mathrm{S}-\mathrm{N}$ at the east side of the city. The wind state clusters of this pattern begin their development around noon and die close to midnight, and their population reached a maximum value between the hours 17 and 18. Doran and Zhong [39] described the main characteristics of a gap wind system in the southeastern corner of the Mexico City basin that produces low-level jets and that occurs regularly during the late winter. The available evidence suggests that these winds are generated primarily by temperature differences between the basin and its surroundings, similar to the wind systems studied by Kimura and Kuwagata [40].

WP5. Westerly Winds. This wind pattern occurred with the smallest annual average frequency (4\%). It was observed only during the first semester of the year, mainly during spring season (12\%). Its wind states represent light air (29\%) and light breeze (55\%), convergent $(\gamma<0,71 \%)$ winds, with very 
slight predominance of cyclonic vorticity $(\omega>0,53 \%)$, and with a westerly flow component in almost all the city quadrants. During winter, the wind states of this pattern occurred only from hour 10 up to hour 22, but during spring they were observed all day. The origin of these local winds may be closely related to the subtropical jet stream of winter [41] or with the westerlies that are permanently occurring in subtropical and middle latitudes.

WP6: Afternoon Northerly Winds. This wind pattern had an annual average frequency of $13 \%$ in the study period. It was observed systematically throughout the year for each year, especially during autumn, with a relative frequency of $16 \%$. The trends of the cluster populations of this pattern are very similar to those of the southerly gap winds (WP4), but now the wind states describe light breeze (76\%) winds blowing (in average) from north (69\%), northeast (17\%) and northwest (12\%), with cyclonic vorticity $(68 \%)$ and are predominantly convergent (94\%). The wind states of this pattern fell mainly within the period 10-22 h, with a maximum value around the hour 18.

WP7: Midnight Katabatic Winds. The annual average frequency of this wind pattern was $14 \%$ and it was observed systematically throughout the year. Its wind states developed between sunset and sunrise and the population trends show a maximum value around midnight. These wind states represent cyclonic and convergent winds which, in the western quadrants of the city, flow by gravity downslope from Sierra de las Cruces (W) and Sierra del Ajusco-Chichinautzin (SW and S) toward the city; while in the eastern quadrants, the katabatic winds from Sierra Nevada developed superposed to the late afternoon gap winds (southerly or northerly) guided by the $\mathrm{S}-\mathrm{N}$ ventilation channel of the city. This pattern, in fact, should appear split into two smaller patterns, if there are a number of clusters larger than six.

De Foy et al. [16] reported a cluster analysis carried out to identify the main wind circulation modes in the metropolitan area of Mexico City for the period of the MILAGRO campaign (March 2006) and also for a period of 10 years before, but considering only the warm dry season (15 February to 15 May). They also used the hourly wind data reported by the meteorological network REDMET. Attending to the availability of wind data, the meteorological stations they selected were: XAL, TLA, EAC, TAC, PLA, PED, CES, and MER. Their data validation produced 16,791 hourly events of a total of 21,168 of the period of time they considered. The clusters were first created with the complete linkage hierarchical method. The resulting medians were used to seed the k-means clustering algorithm. The distance between two wind fields for the k-means algorithm was calculated by taking the root mean square difference of all the data points. The number of clusters was chosen to be 8 as this coincided with a local minimum in maximum distance within the clusters. The clusters were separated into three drainage types: $S f_{c}$ Drain1, $S f_{c}$ Drain2, and $S f_{c}$ Drain3, three northerly to easterly types: Sfc Northeast, Sfc East, and Sfc North, and two southerly types: Sfc South and Sfc Southwest. The clustering method automatically recognized the diurnal structure of the basin wind circulation, with a clear progression from $S f c$ Drain1 to $S f c$ Drain2, and then to $S f c$ Drain3. Then, the circulation goes to the $S f c$ East and $S f_{c}$ Northeast clusters before being replaced by either the $S f c$ North or $S f c$ South cluster in the mid to late afternoon and some Sfc Southwest clusters in the late afternoons.

A comparison of the wind patterns WP1-WP7 with those reported by de Foy et al. [16] shows the following important similarities and differences, which are also summarized in Table 7. The wind pattern WP7 (Midnight Katabatic Winds) coincides with Sfc Drain1; WP1 (Early Morning Katabatic Winds) coincides with $S f_{c}$ Drain2; WP2 (Northeasterly and Easterly Winds) contains the clusters $S f c$ 
Northeast and Sfc East; WP6 (Afternoon Northerly Winds) corresponds to Sfc North; and WP4 (Afternoon Southerly Winds) comprises the clusters Sfc South and Sfc Southwest. The wind patterns WP3 (Midday Northerly Winds) and WP5 (Westerly winds) were not reported by de Foy et al. [16]. These two patterns, however, took place within the three month period they considered (15 February to 15 May) with occurrence frequencies around $10 \%$, which is larger than the frequency of the wind pattern WP4 (Afternoon Southerly Winds) that comprises the clusters Sfc South and Sfc Southwest of de Foy et al. Our method, otherwise, could not recognize the cluster Sfc Drain3 obtained by de Foy et al.

Table 7. Correspondence between the Mexico City wind circulation patterns that were identified in this work and those found by de Foy et al. [16], both using cluster analysis techniques.

\begin{tabular}{cc}
\hline $\begin{array}{c}\text { This Work } \\
(\mathbf{2 0 0 1 - 2 0 0 6 )}\end{array}$ & $\begin{array}{c}\text { De Foy } \text { et al. [16] } \\
\text { (Warm Dry Season, 1998-2006) }\end{array}$ \\
\hline WP7 & Sfc Drain1 \\
WP1 & Sfc Drain2 \\
WP2 & Sfc Drain3 \\
WP3 & $S f c$ Northeast \\
WP4 & Sfc East \\
WP5 & Sfc North \\
WP6 & $S f c$ South \\
& $S f c$ Southwest \\
\hline
\end{tabular}

\section{Conclusions}

The Mexico City local wind events from 2001-2006 were analyzed to identify and characterize their circulation patterns, and to estimate their occurrence probabilities. The study was carried out by employing a lattice wind model approach at the meso- $\beta$ scale and hierarchical cluster analysis. Hourly wind data provided by the meteorological network of the Mexico City Metropolitan Area were used. The systematic availability of high quality wind data at this network makes it possible to perform studies for longer time periods with no additional technical problems. The conceptual simplicity of this analysis approach allows its application also for practical goals such as identifying and selecting wind scenarios in air quality assessment studies [3,42].

On average, the general characteristics of Mexico City model wind events were the following. Nine percent were calm, $65 \%$ light air, and $26 \%$ light breeze. The west-east wind component was positive for $52 \%$ of the wind events, indicating a very slight predominance of winds with a westerly flow component. The south-north wind component was negative for $66 \%$ of the events, revealing clear predominance of winds with a northerly flow component. Wind divergence was negative for $78 \%$ of the hourly wind events, highlighting that convergent winds prevailed during nighttime, but also during $50 \%$ of daylight hours, when it should be expected that the flow induced by the urban heat island would be weakened by the turbulent mixing atmospheric processes. Wind vorticity was positive during $61 \%$ of the wind events of the period, showing predominance of cyclonic winds. 
Application of hierarchical cluster analysis to the set of the Mexico City wind states (described by the attributes $u, v, \gamma$, and $\omega$ ) consented to identify seven wind circulation patterns and to estimate their occurrence frequencies on the seasonal and annual basis. These wind patterns and their annual occurrence frequencies were: WP1: Early Morning Katabatic Winds (26\%), WP2: Easterly and Northeasterly Winds (20\%), WP3: Midday Northerly Winds (11\%), WP4: Afternoon Southerly Winds (9\%), WP5. Westerly Winds (4\%), WP6: Afternoon Northerly Winds (13\%), and WP7: Midnight Katabatic Winds (14\%). The effects of the regional topography, the urban heat island, and the thermal interaction between the city and its surroundings were reflected, at least, by the patterns WP1, WP4, and WP7. The effect of the general circulation of atmosphere at the horse latitudes and below the Tropic of Cancer (trade winds, Caribbean low level jet, subtropical jet stream of winter, and prevailing westerlies) was also reflected by these patterns, for example, by WP2 and WP5. Agreement with the qualitative wind circulation modes described by Jauregui [5,6], Klaus et al. [15,36], Doran et al. [9], Doran and Zhong [39], and de Foy et al. [16] was found, although our comparison was done with more detail compared to the results from de Foy et al., because no other work where cluster analysis is used to identify the Mexico City wind patterns was found in literature. In the present work, as an important difference with respect to the above mentioned studies, it is stressed that a notably larger wind database was considered in the analysis (a set composed of six years of hourly wind data from a 10 station network) that it was possible to give a detailed and quantitative characterization of the wind circulation patterns in terms of the attributes of the extended wind state concept $(u, v, \gamma, \omega)$, two of which $(\gamma, \omega)$ never were used before for these purposes, and also that an estimation of the probabilities of occurrence of the wind patterns was provided. The method is conceptually quite simple and allowed for an objective, systematic and easy identification of the Mexico City wind circulation patterns.

\section{Acknowledgments}

The authors wish to express their gratitude to M. Isabel Saavedra and David Adams (CCA-UNAM) for helping in revising this article. Enlightening comments and suggestions from Professors Sasha Madronich (NCAR Earth System Laboratory, Regional \& Process Modeling) and Benjamin de Foy (Department of Earth and Atmospheric Sciences, Saint Louis University) are acknowledged. One of the authors (SCS) would like to thank Angel Fierros Palacios (Director of DEA-IIE) for his encouragement, support and guidance.

\section{Author Contributions}

Carreón-Sierra and Salcido have carried out the main part of writing, but all coauthors have contributed extensively to the text. The research has mainly been carried out by all co-authors, comprising both modelling work and also data analysis.

\section{Conflicts of Interest}

The authors declare no conflict of interest. 


\section{References}

1. Salcido, A.; Celada-Murillo, A.T.; Villegas-Martinez, R.; Salas-Oviedo, H.; Sozzi, R.; Georgiadis, T. A Micrometeorological Data Base for the Mexico City Metropolitan Area. Nuovo Cim. 2003, 26, 317-355.

2. Salcido, A.; Sozzi, R.; Castro, T. Least squares variational approach to the convective mixing height estimation problem. Environ. Model. Softw. 2003, 18, 951-957.

3. Salcedo, D.; Castro, T.; Ruiz-Suárez, L.G.; García-Reynoso, A.; Torres-Jardón, R.; Celada, A.T.; Torres-Jaramillo, A.; Mar-Morales, B.E.; Salcido, A.; Carreón-Sierra, S.; et al. Study of the regional air quality south of Mexico City (Morelos state). Sci. Total Environ. 2012, 414, 417-432.

4. Aispuro Coronel, J. A. Informe de Trabajo 2007; Secretaria de Desarrollo Urbano y Vivienda (SEDUVI), Gobierno del Distrito Federal, Mexico City, Mexico, 2007.

5. Jauregui, E. Heat Island Development in Mexico City. Atmos. Environ. 1997, 31, 3821-3831.

6. Jauregui, E. Local wind and air pollution interaction in the Mexico basin. Atmósfera 1988, 1, 131-140.

7. Bossert, J.E. An Investigation of Flow Regimes Affecting the Mexico City Region. J. Appl. Meteorol. 1997, 36, 119-140, doi:10.1175/1520-0450(1997)036<0119:AIOFRA>2.0.CO;2.

8. Fast, J.D.; Zhong, S. Meteorological factors associated with inhomogeneous ozone concentrations within the Mexico City basin. J. Geophys. Res. 1998, 103, 18927-18946.

9. Doran, J.C.; Abbott, S.; Archuleta, J.; Bian, X.; Chow, J.; Coulter, R.L.; de Wekker, S.F.J.; Edgerton, S.; Elliott, S.; Fernandez, A.; et al. The IMADA-AVER Boundary Layer Experiment in the Mexico City Area. Bull. Am. Meteorol. Soc. 1998, 79, 2497-2508, doi:10.1175/1520-0477 (1998)079<2497:TIABLE>2.0.CO;2.

10. De Foy, B.; Caetano, E.; Magaña, V.; Zitácuaro, A.; Cárdenas, B.; Retama, A.; Ramos, R.; Molina, L.; Molina, M. Mexico City basin wind circulation during the MCMA-2003 field campaign. Atmos. Chem. Phys. 2005, 5, 2267-2288, doi:10.5194/acp-5-2267-2005.

11. Fast, J.D.; de Foy, B.; Acevedo Rosas, F.; Caetano, E.; Carmichael, G.; Emmons, L.; McKenna, D.; Mena, M.; Skamarock, W.; Tie, X.; et al. A meteorological overview of the MILAGRO field campaigns. Atmos. Chem. Phys. 2007, 7, 2233-2257.

12. Salcido, A.; Celada-Murillo, A.T.; Castro, T. A meso- $\beta$ scale description of surface wind events in Mexico City during MILAGRO 2006 campaign. In IASTED Technology Conferences, Proceedings of the Second IASTED International Conference on Environmental Management and Engineering EME 2010, Banff, AB, Canada, 15-17 July 2010; Alhajj, R.S., Leung, V.C.M., Petela, R., Saif, M., Thring, R., Eds.; Acta Press: Banff, AB, Canada, 13 August 2010; Paper number 699-041, pp. 820-827.

13. Celada-Murillo, A.; Carreón-Sierra, S.; Salcido, A.; Castro, T.; Peralta, O.; Georgiadis, T. Main Characteristics of Mexico City Local Wind Events during the MILAGRO 2006 Campaign within a Meso- $\beta$ Scale Lattice Wind Modeling Approach. ISRN Meteorol. 2013, 14, doi:10.1155/2013/605210. 
14. Salcido, A.; Carreón-Sierra, S.; Celada-Murillo, A.T. A Brief Clustering Analysis of the Mexico City Local Wind States Occurred During the MILAGRO Campaign. In Proceedings of the 4th IASTED International Conference on Environmental Management and Engineering EME 2014, Banff, AB, Canada, 16-17 July 2014.

15. Klaus, D.; Poth, A.; Voss, M.; Jauregui, E. Ozone distributions in Mexico City using principal component analysis and its relation to meteorological parameters. Atmósfera 2001, 14, 171-188.

16. De Foy, B.; Fast, J.D.; Paech, S.J.; Phillips, D.; Walters, J.T.; Coulter, R.L.; Martin, T.J.; Pekour, M.S.; Shaw, W.J.; Kastendeuch, P.P.; et al. Basin-scale wind transport during the MILAGRO field campaign and comparison to climatology using cluster analysis. Atmos. Chem. Phys. 2008, 8 , 1209-1224, doi:10.5194/acp-8-1209-2008.

17. Huth, R.; Beck, C.; Philipp, A.; Demuzere, M.; Ustrnul, Z.; Cahynová, M.; Kyselý, J.; Tveito, O.E. Classifications of Atmospheric Circulation Patterns. Ann. N. Y. Acad. Sci. 2008, 1146, 105-152, doi:10.1196/annals.1446.019.

18. Davis, R.E.; Walker, D.R. An Upper-Air Synoptic Climatology of the Western United States. J. Clim. 1992, 5, 1449-1467.

19. Weber, R.O.; Kauffmann, P. Automated Classification Scheme for Wind Fields. J. Appl. Meteorol. 1995, 34, 1133-1141.

20. Kauffmann, P.; Weber, R.O. Classification of Mesoscale Wind Fields in the MISTRAL Field Experiment. J. Appl. Meteorol. 1996, 35, 1663-1979.

21. Kauffmann, P.; Whiteman, C.D. Cluster-Analysis Classification of Wintertime Wind Patterns in the Grand Canyon Region. J. Appl. Meteor. 1999, 38, 1131-1147.

22. Weber, R.O.; Furger, M. Climatology of Near-Surface Wind Patterns over Switzerland. Int. J. Climatol. 2001, 21, 809-827.

23. Kastendeuch, P.P.; Kaufmann, P. Classification of summer wind fields over complex terrain. Int. J. Climatol. 1997, 17, 521-534.

24. Kastendeuch, P.P.; Najjar, G. Upper-air wind profiles investigation for tropospheric circulation study. Theor. Appl. Climatol. 2003, 75, 149-165.

25. Salcido, A.; Carreón-Sierra, S.; Georgiadis, T.; Celada-Murillo, A.T.; Castro, T. Lattice Wind Description and Characterization of Mexico City Local Wind Events. Period 2001-2006. Climate 2016, 3 , in press.

26. Ward, J.H. Hierarchical grouping to optimize an objective function. J. Am. Stat. Assoc. 1963, 58, 236-244, doi:10.1080/01621459.1963.10500845.

27. Aldenderfer, M.S.; Blashfield, R.K. Cluster Analysis, 5th ed.; SAGE Publications Inc.: Newbury Park, CA, USA, 1984.

28. Shaefer, J.T.; Doswell, C.A., III. On the Interpolation of a Vector Field. Mon. Weather Rev. 1979, $107,458-476$.

29. Kaufman, L.; Rousseeuw, P.J. Finding Groups in Data. An Introduction to Cluster Analysis; John Wiley \& Sons Inc.: Hoboken, NJ, USA, 2005.

30. Milligan, G.W.; Cooper, M.C. A study of standardization of variables in cluster analysis. $J$. Classif. 1988, 5, 181-204.

31. Lance, G.H.; Williams, W.T. A General Theory of Classificatory Sorting Strategies. I. Hierarchical Systems. Comp. J. 1966, 9, 373-380. 
32. Everitt, B.S.; Landau, S.; Leese, M. Cluster Analysis, 5th ed.; Arnold: London, UK, 2001.

33. Lohninger, H. The Software Package DataLab; Software Development Lohninger \& Epina Software Labs, Epina GmbH: Pressbaum, Austria, 2013.

34. Informes Climatológicos Ambientales del Valle de México 2001-2006; Sistema de Monitoreo Atmosférico. Secretaría del Medio Ambiente. Gobierno del Distrito Federal. Available online: http://www.sedema.df.gob.mx/ and http://www.aire.df.gob.mx/ (accessed on 18 July 2105).

35. Carreón-Sierra, S. Taxonomía del Viento en Superficie en la Ciudad de México con un Modelo Celular de Representación a Escala Meso- $\beta$. Periodo 2001-2006. Bachelor's Thesis, Matemáticas Aplicadas y Computación, FES Acatlán, UNAM, Mexico City, Mexico, 2014.

36. Klaus, D.; Jauregui, E.; Poth, A.; Stein, G.; Voss, M. Regular circulation structures in the tropical basin of Mexico City as a consequence of the urban heat island effect. Erdkunde 1999, 53, 231-243, doi:10.3112/erdkunde.1999.03.04.

37. Muñoz, E.; Busalacchi, A.J.; Nigam, S.; Ruiz-Barradas, A. Winter and Summer Structure of the Caribbean Low-Level Jet. J. Clim. 2008, 21, 1260-1276.

38. Wolter, K. The Southern Oscillation in Surface Circulation and Climate over the Tropical Atlantic, Eastern Pacific, and Indian Oceans as Captured by Cluster Analysis. J. Clim. Appl. Meteorol. 1987, 26, 540-558.

39. Doran, J.C.; Zhong, S. Thermally Driven Gap Winds into the Mexico City Basin. J. Appl. Meteorol. 2000, 39, 1330-1340, doi:10.1175/1520-0450(2000)039<1330:TDGWIT>2.0.CO;2.

40. Kimura, F.; Kuwagata, T. Thermally Induced Wind Passing from Plain to Basin over a Mountain Range. J. Appl. Meteorol. 1993, 32, 1538-1547.

41. Krishnamurti, T.N. The Subtropical Jet Stream of Winter. J. Meterol. 1960, 18, 172-191.

42. Peralta, O.; Castro, T.; Durón, M.; Salcido, A.; Celada-Murillo, A.T.; Navarro-González, R.; Márquez, C.; García, J.; de la Rosa, J.; Torres, R.; et al. $\mathrm{H}_{2} \mathrm{~S}$ emissions from Cerro Prieto geothermal power plant, Mexico, and air pollutants measurements in the area. Geothermics 2013, 46, 55-65, doi:10.1016/j.geothermics.2012.12.001.

(C) 2015 by the authors; licensee MDPI, Basel, Switzerland. This article is an open access article distributed under the terms and conditions of the Creative Commons Attribution license (http://creativecommons.org/licenses/by/4.0/). 